Andrews University

Digital Commons @ Andrews University

Master's Theses

Graduate Research

2019

\title{
Ethnography: Andrews University Lady Cardinals Soccer Team and Group Dynamics
}

Liz Dominguez

Andrews University, lizd@andrews.edu

Follow this and additional works at: https://digitalcommons.andrews.edu/theses

Part of the Communication Commons, and the Sports Studies Commons

\section{Recommended Citation}

Dominguez, Liz, "Ethnography: Andrews University Lady Cardinals Soccer Team and Group Dynamics" (2019). Master's Theses. 137.

https://dx.doi.org/10.32597/theses/137

https://digitalcommons.andrews.edu/theses/137

This Thesis is brought to you for free and open access by the Graduate Research at Digital Commons @ Andrews University. It has been accepted for inclusion in Master's Theses by an authorized administrator of Digital Commons @ Andrews University. For more information, please contact repository@andrews.edu. 


\title{
ETHNOGRAPHY: ANDREWS UNIVERSITY LADY CARDINALS SOCCER TEAM AND GROUP DYNAMICS
}

\author{
by \\ Liz Dominguez
}

Chair: Desrene Vernon-Brebnor 


\title{
ABSTRACT OF GRADUATE STUDENT RESEARCH
}

Thesis

\author{
Andrews University \\ Department of Visual Art, Communication \& Design
}

Title: ETHNOGRAPHY: ANDREWS UNIVERSITY LADY CARDINALS SOCCER TEAM AND GROUP DYNAMICS

\section{Problem}

\section{ABSTRACT}

The Andrews University Lady Cardinals soccer team has a reputation of having back to back unsuccessful seasons. Hypotheses and research questions were formulated, and the answers provide further insight into the difficulties the team experienced during the 2018 soccer season. They are as follows:

\section{Research Hypotheses:}

1. Team members with higher skill levels will be more highly valued by the coach and other team members. 
2. If the team does not have an adequate preseason, it will not be prepared to play as a team, thus it will have difficulty having a successful season.

3. Players who have positive interactions off the field, play better on the field due to an established level of trust.

\section{Research Questions:}

4. How does the number of match-minutes played affect team members' morale/team spirit?

5. How does external support impact members morale/team spirit?

6. What factors influence the commitment and retention of team members?

\section{Purpose}

The purpose of this ethnographic study is to understand the different barriers to successful team building specifically in the area of sports, by looking at the Andrews University Lady Cardinals women's soccer team. This research focuses on internal and external factors that impact the Lady Cardinals team success in light of the conceptual framework of Tuckman's group stages: forming, storming, norming, performing, and adjourning.

\section{Method}

The data was collected through observations made during the 2018 soccer season for the duration of 14 weeks. Data was documented and organized using various charts including a Daily Observation Chart and a Match Minutes Played Chart. The data collected through observations 
were correlated with data collected through post-season interviews. The interviews consisted of 15 out of the 16 Cardinal players and three out of the four coaches. All interviews were conducted face-to-face except for two of the coaches who responded to questions via email. After the interviews were conducted, they were then transcribed. The analysis was made possible through the use of the software program NVIVO which provided an effective way of organizing the various themes that emerged.

\section{Conclusion}

The study confirmed the hypotheses and answered the research questions. Apart from the group dynamics originally being studied, ineffective leadership emerged as a significant theme throughout the research especially regarding leadership communication between coaching staff and players. Considering Tuckman's theory, the team's longest stage is the formation stage, and the team barely reaches the performing stage as soon as the season is ending. There is no adjourning stage. Various barriers to successful team building were found, both internal and

external, which in turn, affected the team's overall season and performance. The data collected also revealed concerns in regard to Title IX and male coach-to-female player relational dynamics.

\section{Subject Area}

Communication-Interpersonal and Leadership; Group management and Leadership; Group formation and dynamics; Andrews University Athletics; Sports - Soccer 
Andrews University

College of Arts and Sciences

\title{
ETHNOGRAPHY: ANDREWS UNIVERSITY LADY CARDINALS SOCCER TEAM AND GROUP DYNAMICS
}

\author{
A Thesis \\ Presented in Partial Fulfillment \\ of the Requirements for the Degree
}

Master of Arts

By

Liz Dominguez

April 2019 
(C) Copyright by Liz Dominguez 2018

All Rights Reserved 


\title{
ETHNOGRAPHY: ANDREWS UNIVERSITY LADY CARDINALS SOCCER TEAM AND GROUP DYNAMICS
}

A thesis presented in partial fulfillment of the requirements for the degree

\author{
Master of Arts
}

by

\section{Liz Dominguez}

APPROVAL BY THE COMMITTEE:

Desrene Vernon-Brebnor, Ph.D.

Lynn Caldwell, M.A.

Heather Day, Ph.D.

Date approved

vii 


\section{DEDICATION}

Thank you God the Father, Jesus, and Holy Spirit for bringing me this far.

All the glory goes to you.

This God-given accomplishment is for my family. Father and mother, Douglas and Gloria, who have exemplified the love of Jesus in my life and have so selflessly devoted their lives to the service of God and to others. And beautiful sister Jamie whom I hope to positively inspire every day.

I would like to acknowledge my committee. My advisor and committee chair, Mrs. Desrene Vernon-Brebnor. It has been an honor being your student. I cannot thank you enough for your leadership and dedication. Your professionalism is something to admire. I aspire to touch lives the way you have touched mine. Thank you for being so patient with me and for sharing so many special moments with me throughout this journey. I thank God for you. Also, professor Lynn Caldwell, thank you for your attention and willingness to help in every way possible. You also inspire me to live a life that is full of joy and smiles. I am thankful for you and your loving spirit. And Mrs. Heather Day, thank you for your insight and your sincere advice. You inspire me to have a passion for others and to view others the way that God sees them. I am grateful for you and the way you have also touched my life.

It has been an honor to work with all of you and in simply knowing that you all believed in me. You have all shown me God's goodness. Thank you for being instruments of love for students like me. 


\section{Table of Contents}

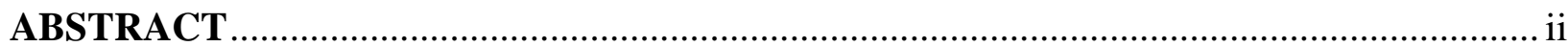

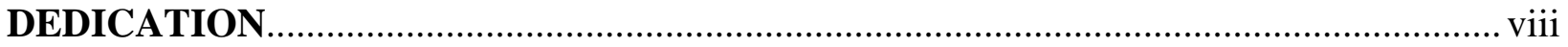

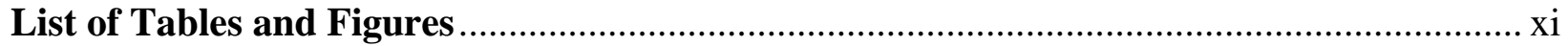

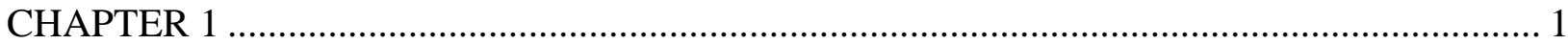

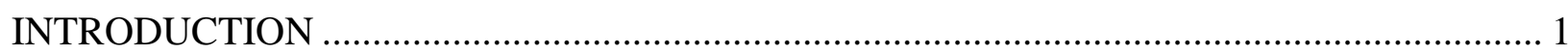

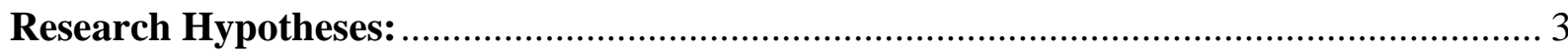

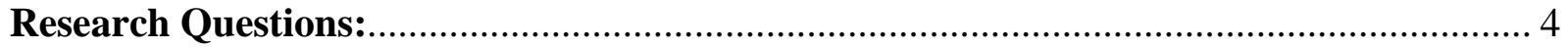

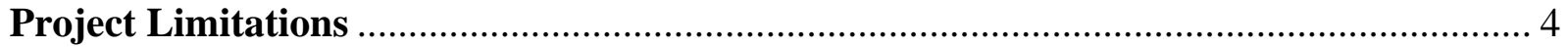

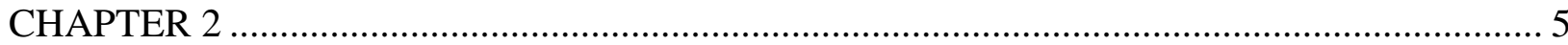

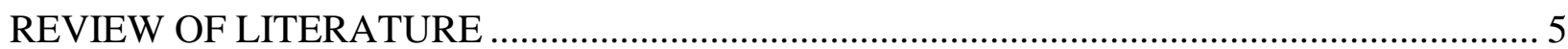

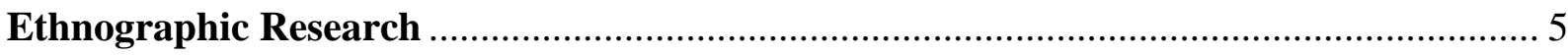

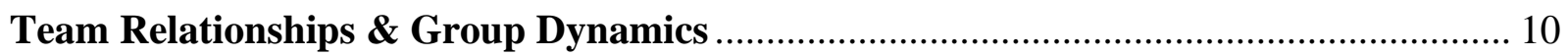

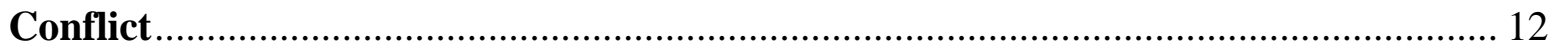

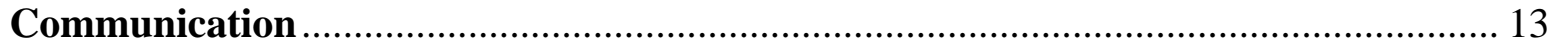

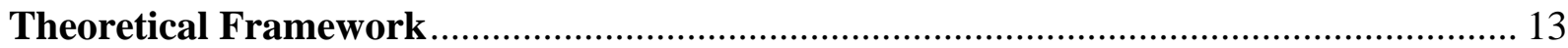

Tuckman's Stages of Group Development ………………………………………….... 13

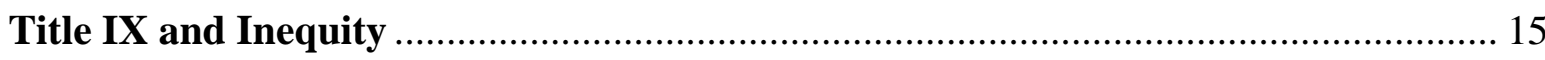

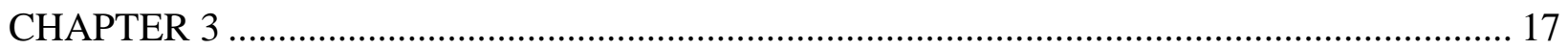

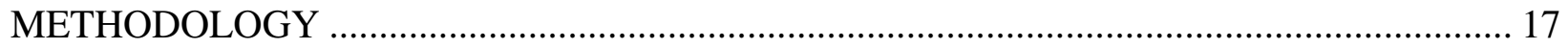

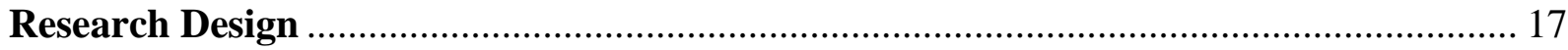

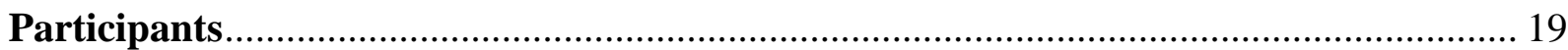

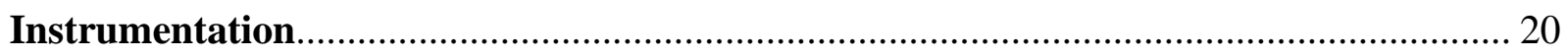

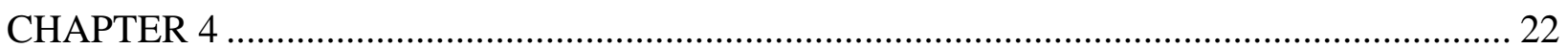

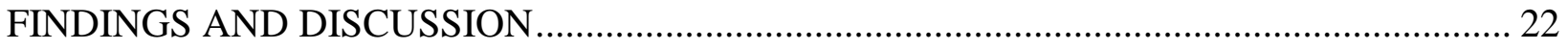

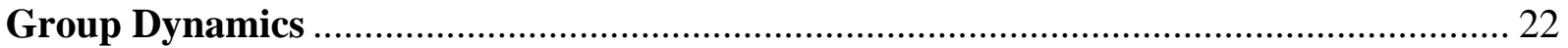




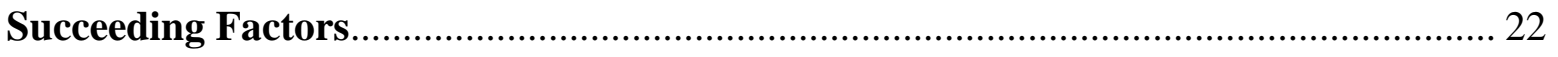

Players Valued by Coach and Team Members ........................................................ 24

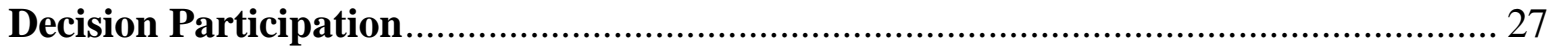

Inclusive Communication Versus Exclusive Communication ........................................ 29

Match Minutes Played ........................................................................................... 38

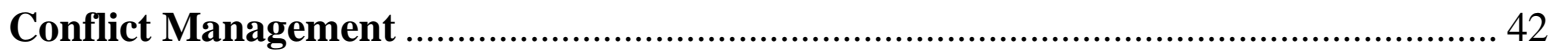

Preseason: Tuckman's Stages of Group Formation ........................................................ 48

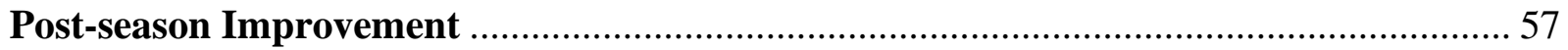

Ineffective Communication in Leadership …………................................................ 57

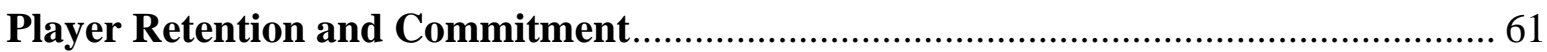

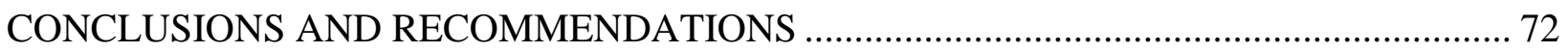

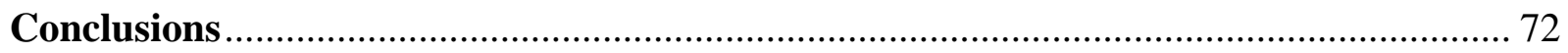

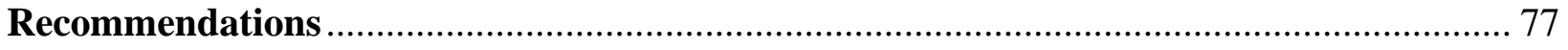

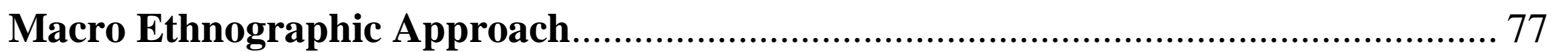

Effective Organizational Communication .................................................................. 77

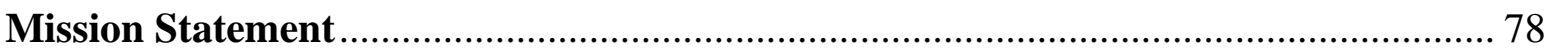

Male Coach-to-Female Players Relational Dynamics ……………………………...... 78

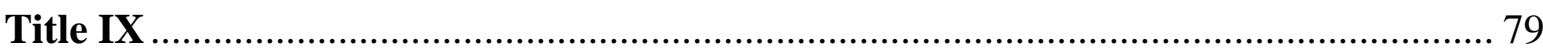

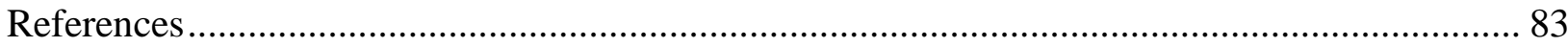

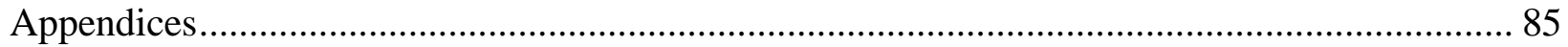

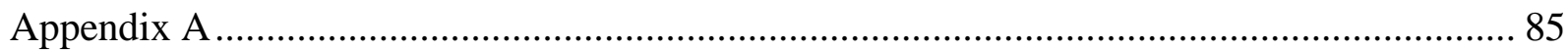

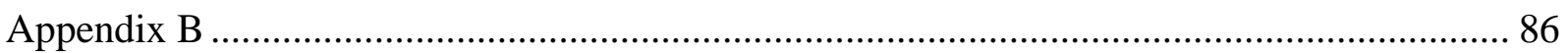

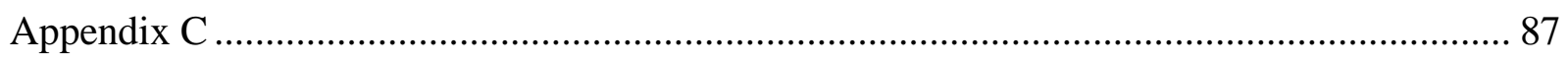

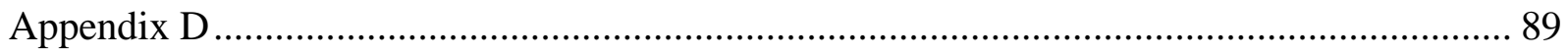

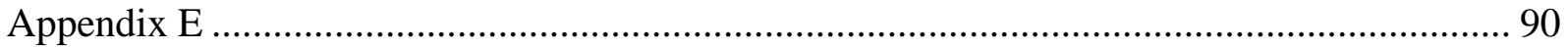




\section{List of Tables and Figures}

Figure 1 Summary of Tuckman's Stages of Group Development.

Figure 2 Factors That Helped the Andrews University Lady Cardinals Succeed According to

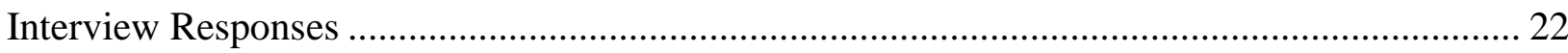

Figure 3 Interview Results of Inclusive and Exclusive Communication Instances During the 2018

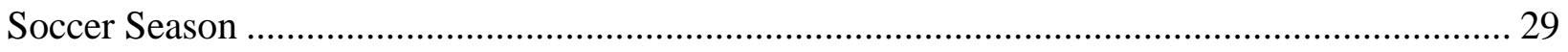

Figure 4 Player Profile Summary for the 2018 Soccer Season .............................................. 36

Figure 5 Interview Responses About the Andrews University Lady Cardinals’ Conflict

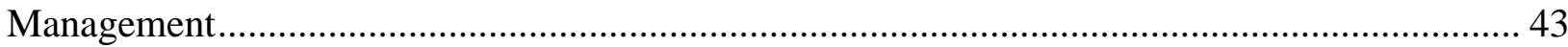

Figure 6 Tuckman's Stages of Group Formation and the Lady Cardinals' 2018 Soccer Season. 49

Figure 7 Andrews University Lady Cardinals' Attendance Progression During the 2018 Soccer

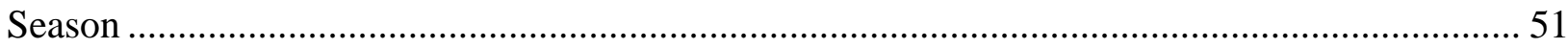

Figure 8 Positive and Negative Factors that Affect Player Commitment and Retention According to the Andrews University Women's Soccer Team’s Interview Responses 61 


\section{CHAPTER 1}

\section{INTRODUCTION}

The purpose of this study is to understand the different barriers to successful team building in the sport of soccer. Specifically focusing on what factors were present in the Andrews University Lady Cardinals soccer that hindered the development of group dynamics. For the duration of this project, I observed the different aspects that affect team members' morale/team spirit, and relationship building such as player retention, the length of the preseason, and minutes played during competitive season games. As a result of this ethnography, there is more understanding regarding the various group dynamics that take place in a team setting and the value that each stage of a group coming together holds specifically pertaining to Andrews University soccer.

I have been an active member of the Andrews University Lady Cardinals soccer team for approximately three years before the season in which the ethnography took place (fall semester 2018). I became a member of the team for the season of 2015. That season, the Athletic Director informed the men's team and the women's team that it was the eighth year of the Andrews University athletics program. He was the creator of the program and he stated that this program was his pride and joy. This would mean that the year 2018 is the $12^{\text {th }}$ year of the athletic program. Needless to say, it is fairly new. The season of 2016, I joined the team for a second time. Then finally, I joined the season of 2017 which was the season in which I was most active 
on the team. That season, I was named captain along with another one of my teammates. We were also chosen by our coach to be assistant coaches. At the end of the season, when awards and recognitions were given to the team members, I received MVP of the year. For the duration of my active participation on the Lady Cardinals soccer team, I saw and experienced the challenges, both internal and external, of being on an official school sports team. Internally, the team faced some challenges coming together interpersonally/relationally as a team especially in the beginning because people would join and then leave after a couple of practices due to the lack of incentives to play. Consequently, the team would constantly change players, which made it difficult to learn how to work together. It is important to note that Andrews University is a private school that focuses mainly on education/academics. Therefore, the school itself is evidently different from other schools the athletic teams play against in the National Collegiate Athletic Association (NCAA). In comparison to other universities, Andrews University has not viewed athletics as a top priority in regard to the distribution of monetary resources. This, amongst other things, affects the athletics department. Another issue is that sometimes the team would not have enough girls to form a solid team (soccer requires 11 players on the field plus additional players as substitutions). Sometimes the team would barely be able to gather 11 players. For this reason, the coach would be scrambling to recruit more girls to be on the team. This meant that during the season, even after the first official match had been played, more girls would start coming to practice and incorporating themselves to the team. This would sometimes cause those "late players" to not be very well integrated with the team. Externally, I watched the resources diminish as the years went by. I have seen and experienced the conditions of the fields the soccer team is required to train on. Above all, I have witnessed the dwindling overall support the Lady Cardinals soccer team has had during the three seasons I have been involved. I know 
that there are a lot of areas that can be improved, not just for the women's soccer team at Andrews, but the athletic department as a whole. However, I wanted to focus on the Lady Cardinals since it is what I have been the most involved with. Therefore, the purpose of this ethnographic study is to provide accurate data that brings awareness to the internal and external challenges the Lady Cardinal soccer team faces. The information collected can be used for further improvement of the team and athletic department if reviewed by staff, coaches, and team members.

In order to control researcher's bias, there are certain steps that I have taken. Primarily, for the season of 2018, I was not an active member in any of the decisions made for the team. Previous years, I had somewhat of a voice because of my position as both captain and assistant coach. However, this year, due to eligibility issues, I was not able to be an active player on the team. After gaining approval from the coach, I was able to conduct the ethnographic study through observation and being with the players as well as post-season interviews, but I myself was not officially a part of the team. This was good because I was close enough to observe and become integrated socially, yet I was able to keep from imposing my own opinions about the players or the coaches in order to ensure accurate research findings.

This project seeks to answer the following hypotheses and research questions:

\section{Research Hypotheses:}

1. Team members with higher skill levels will be more highly valued by the coach and other team members.

2. If the team does not have an adequate preseason, it will not be prepared to play as a team, thus it will have difficulty having a successful season. 
3. Players who have positive interactions off the field, play better on the field due to an established level of trust.

\section{Research Questions:}

4. How does the number of match-minutes played affect team members' morale/team spirit?

5. How does external support impact members morale/team spirit?

6. What factors influence the commitment and retention of team members?

\section{Project Limitations}

Due to the inconsistency of player attendance this soccer season, certain limitations were placed in order to be included in the study. Players had to attend at least 40 percent of the official matches (approximately four out of nine games) and $80 \%$ of practices sessions.

Furthermore, this ethnographic study will provide insight to the factors regarding group dynamics and communication that affect the success of the Lady Cardinals soccer team, and which will be valuable to understand in order to improve the team in the following future seasons. 


\section{CHAPTER 2}

\section{REVIEW OF LITERATURE}

\section{Ethnographic Research}

One of the main aspects of ethnographic research is participant observation. According to Okamura (2009), "participant observation must be conducted over an extended length of time [... and] requires the total involvement of the fieldworker in the lives of the people being studied" (p. 29). I experienced the value of this in integrating myself with the team of players this season. I was able to understand the depth of relationships in a team setting where people come together for a prolonged period of time while being able to study each player's experience individually as well. Each person's experience is so unique, yet together as a whole, the team's experience is unique in relation to each other. Therefore, observations must be made both individually and holistically. Okamura (2009) continues by explaining that participant observation, "means taking part in their daily activities, following their customary norms of behavior, and engaging in interactions through their language" (p. 29). During practices and games, I engaged with the players as much as possible in order to visualize patterns of behavior, and also to understand them as individuals in studying their language. One of the areas of communication that I studied within the dialogue of the participants was inclusive communication versus exclusive communication, and that could only be accomplished through deep participant observation. 
In summary, "such extended and intimate interaction with the people enables the ethnographer to make close observations of their life as they experience it since in order to understand an activity or cultural pattern sufficiently one has to see it as its participants do" (Okamura, 2009, p.29). Although everyone's experience is different, participant observation allows the researcher to understand and better relate to their experiences.

One example of a successful ethnographic study was conducted on major depressive disorder (MDD) patients. It is called the IMPACT (Investigating MDD Patients' Accounts of Cognitive Symptoms During Treatment) study. The purpose of the IMPACT study was to understand the impacts on daily life that the cognitive symptoms resulting from major depressive disorder have on MDD patients and the people surrounding them. The researchers wanted to discover the best ways to treat MDD patients and hoped that their ethnographic study would result in the development of new tools and strategies to help those with MDD live a better life (Ebert, Miskowiak, Kloster, Johansen, Eckholm, Wærner, Bruun, 2017).

As for their methods, "The implemented ethnographic methodologies included semi-structured interviews, observations of relevant activities, mapping exercises, and situation card exercises. Research was conducted in the home or office of the participant, depending on the participant type" (Ebert et al., 2017, p. 3). Due to their ethnographic study, the researchers were able to find that MDD does indeed have various impacts on daily living of both those who suffer from the disease and those who are involved with them. After observing the MDD patients who participated in the study, researchers found that these people would forget simple everyday things such as leaving the faucet running. They would also struggle with motivation in doing things that at some point in their lives 
had become a simple routine. Also, due to their mental exhaustion, they would feel the effects on their body with physical exhaustion which would then hinder them in many aspects of their lives such as organization and daily hygiene. The patients who worked were observed in their work settings and researchers found that most if not all of them had difficulty staying on task and prioritizing their work. As for the people who were around these patients, researchers observed that relatives and friends often had to start doing tasks that their loved one with MDD used to perform but could no longer do so due to their mental status. This is just one aspect that was observed to put a strain on MDD patient's relationships with others (Ebert et al., 2017).

In the end, researchers were able to divide the MDD participants into four categories based on their observations and conclusions: Organizer, Expert, Team Player, and Independent. Based on which category MDD patients were placed, those who treated these patients could better understand their patients and formulate a better strategy/plan to treat them (Ebert et al., 2017). This ethnographic study included interviews with these MDD patients along with in-depth observations of their daily experience with MDD. Through interview responses, participants were able to richly describe their experience living with MDD which correlated with the ethnographers' daily recorded observations. In turn, more efficient treatment plans for patients with MDD resulted from this study.

Likewise, in conducting ethnographic research, I hope to describe in detail the barriers to successful team building through the usage of both in-depth daily observations and interviews.

Moreover, ethnographic research is not only conducted in the medical field, but it is also present in the field of sports. Joanna Neville from the University of Florida studied the 
topic of gender through ethnographic research, group interviews, and one-on-one interviews while participating in a collegiate women's ultimate frisbee team (Neville, 2019). This study was conducted to notice masculine hegemonies present in sports, specifically frisbee, in order to understand how women not only deal with these hegemonic conceptions but also how they are able to alter or negotiate these conceptions. According to Neville (2019), "The institution of sport then reproduces gender inequity by normalizing this expected behavior by its social members. The concept of hegemonic masculinity is the most useful starting point of analysis because it speaks to both the pervasive power of hegemony and the expected enactment of masculinity within the institution of sport" (p. 39). When playing on the Lady Cardinals soccer team in the past, I understood that there are plenty of hegemonies in the sport of soccer. It is evident that this is not only present in soccer, but also in other sports such as ultimate frisbee. It is interesting that Neville's topic of study correlates to what I have experienced in the past as well. There are certain concepts that some people have about the sport of soccer in regards to female athletes. In order to understand hegemonic behaviors, Neville interviewed 27 female athletes and observed them and their coach for the spring season. Neville (2019) states:

During the spring season, I attended practices, tournaments, and other social events off the Frisbee field. While at these events extensive fieldwork notes were collected by observing individual interactions, the formation of supportive relationships, language use, mannerisms, dress, and other performance behaviors closely associated with gender. In general, this was accomplished by writing down observations, comments, and scenarios in a notebook that was with me at all times even in tournament play. This was difficult at times because I could not always access 
it during play. At first, some members asked questions about what I was jotting down, but then, as the season progressed, they became less interested with my data collection even in social situations. Gendered actions were noted during fieldwork as they related to a specific encounter or situation. At times, these practices involved others, but at other times, participants simply exhibited individually gendered behavior through personal choice of attire or language usage. After transcribing my observations from my notebook, I organized and coded my notes as I attempted to tease out any themes that described meaningful patterns (p. 46).

Similarly, I took notes on my observation charts and coded my notes to look for the themes found in this study. This also highlights the depth of ethnographic research study. Ethnographic research requires time and accurate data collection. It is significant to be a part of the group being studied even through being present and observing.

Furthermore, Neville (2019) states, "Findings indicate that college women ultimate Frisbee players are able to access the power found in hegemonic masculinity by redefining and reshaping masculine sporting identities into their own. This is a substantial form of resistance to the power of cultural hegemony in sport" (p. 47). The researcher also found that ultimate frisbee is already considered a sport that is not very masculine. Therefore, she concluded that this affects the hegemonic views of the women who play the sport and that perhaps women who participate in other sports are more prone to be affected by masculine hegemonies (Neville, 2019, p. 50.) This study shows a deeper inside look on hegemonies found in sports specifically ultimate frisbee and on a collegiate women's team.

Focusing more on ethnographic research in soccer specifically, a study was conducted on Brazilian soccer and its quality players. According to Damo (2014): 
During the research, [he] showed that in order to become a professional player, candidates need more than a natural inclination towards the practice - what some call a 'gift', and others, 'talent'. In other words, Brazil's success in grooming and training players, which is notorious for both its quantity and quality, was made possible, thanks to a network of multiple and relatively well-articulated devices which go beyond the limits of the soccer field (p. 93).

Sometimes people have the conception that soccer, both on a professional and collegiate level, is only what is done on the soccer field. However, it is evident that there are multiple factors that extend far beyond the soccer field. Through ethnographic research, Damo was able to shed light on some factors that contributed to Brazil's success in developing quality players. One of the findings is that "investments are made in training the physical body through disciplined, strenuous and monotonous routines" (Damo, 2014, p. 99). During the interview process for the study on the Andrews University Lady Cardinals, it was interesting to view the players' perception of how the number of resources can be a barrier to successful team building.

\section{Team Relationships \& Group Dynamics}

One of the concepts of interest for this research study is group identity and cohesion. For example, hostile behavior shown towards rival-team players provides ingroup players with a sense of identity because of the collectiveness in which they demonstrate this type of behavior (Van Doesum, Van Prooijen, Verburgh, \& Van Lange, 2016). In studying the team's collective behavior this season, I was able to observe certain elements that united the group especially regarding topic of conversation. 
According to Praça, Clemente, de Andrade, Perez Morales, \& Greco (2017), "Soccer players' performance is not solely determined by their individual characteristics, but it is also conditioned by the opposition-cooperation relationship between teammates and opponents during the game" (p. 185). The purpose of my study was to find the various barriers to successful team building. In studying the different stages of a team coming together, I was able to see not only the relationship between teammates but also the relationship between the Lady Cardinals and opposing teams through studying their individual characteristics and how they contribute to the team. Research conducted by Praça, Clemente, de Andrade, Perez Morales, \& Greco, (2017) suggests that "optimal levels of cooperation among teammates increase the chances of winning soccer games" (p. 185). It is understandable that optimal levels of cooperation can be found in the performance stage of any group. Therefore, team cooperation is important when understanding the Andrews University Lady Cardinals group stages because in observing the players at peak team performance, the researcher is observing the players at peak optimal cooperation.

According to Posada (2017), "In the field of sport psychology, the study of group dynamics has increased our understanding with regard to the nature and measurement of various group constructs including: cohesion, the coach-athlete relationship, coaching leadership, athlete (peer) leadership, athlete satisfaction, and team attributions" (p. 4). Group dynamics have shaped this ethnographic study because the concept of group dynamics includes the theories that form the theoretical framework that I chose for this study (Tuckman's theory of group stages). In studying the Lady Cardinal's group dynamics, I was able to observe their experiences with each other as each individual participant formed part of the team. Not only that but the cohesion that resulted through player-to-player contact and player-to-coach contact as well. 


\section{Conflict}

One of the aspects of team development and group dynamics is conflict and how the group handles conflict. The definition of conflict is a "strong disagreement between people, groups, etc., that results in often angry argument [or] a difference that prevents agreement: disagreement between ideas, feelings, etc." (Merriam-Webster Online). When describing conflict and group dynamics, Posada (2017) states, "With regard to conflict resolution, participants suggested that conducting team building early in the season, addressing conflict early, having mediators, and holding structured interviews could help to manage conflict" (p. 5). These are all advises that I made a note to observe during the season to see whether the team would have these concepts put in place in order to resolve their conflicts. It is evident that there is more research being done for groups in other fields in regard to conflict resolution. Workgroups are being studied in hopes that what applies to those groups will also apply to sports teams. It would make sense to believe that this can be done because both groups have similarities in group dynamics such as member productivity and relational developments. Yet, there are differences because in work groups there may be a difference in the goals for two or more individuals which causes tension and negative emotions to arise, yet in sports settings, teams usually have the same goal which is to win games. Therefore, there is a difference in studying conflict through that definition which states that between two or more individuals there are perceived incompatible goals (Posada, 2017).

Another important concept about conflict resolution is online communication and face-toface communication, and which one of these is the best one to use when resolving interpersonal conflicts. According to the communication theory of computer-mediated communication (CMC), people usually communicate in a way that is more aggressive when they are communicating online rather than face-to-face. People may communicate with a lack of concern towards the 
other person when resolving conflict online rather than face-to-face (Ishii, 2010, p. 368). It will be interesting to analyze how the Andrews University Lady Cardinals soccer team resolves the conflict that arises during the season of 2018.

\section{Communication}

An essential part of group dynamics and relationship building is communication. According to Van Swol, and A. (2019), "It is apparent that group members need to communicate extensively to coordinate, adapt, and interrelate with one another; because groups and teams are inherently social, the language that arises as members interact with one another is central to their existence and functioning" (p. 4). In any team setting, there is expected to be a difference in communication between player-to-player and player-to-coach.

\section{Theoretical Framework}

There is one main conceptual framework that I used for this study in order to further understand the Andrews University Lady Cardinals soccer team's group dynamics: Tuckman's Stages of Group Development.

\section{Tuckman's Stages of Group Development}

The main theoretical framework used for this study is Tuckman's Stages of Group Development (see Figure 1). 


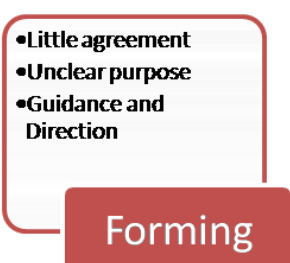

- Little agreement
-Unclear purpose
-Guidance and
Direction

Forming

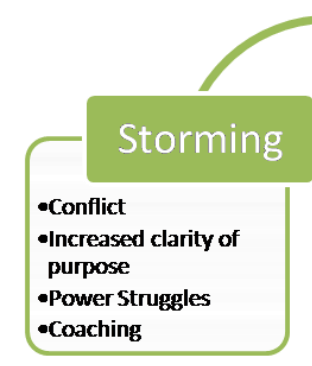

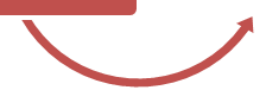
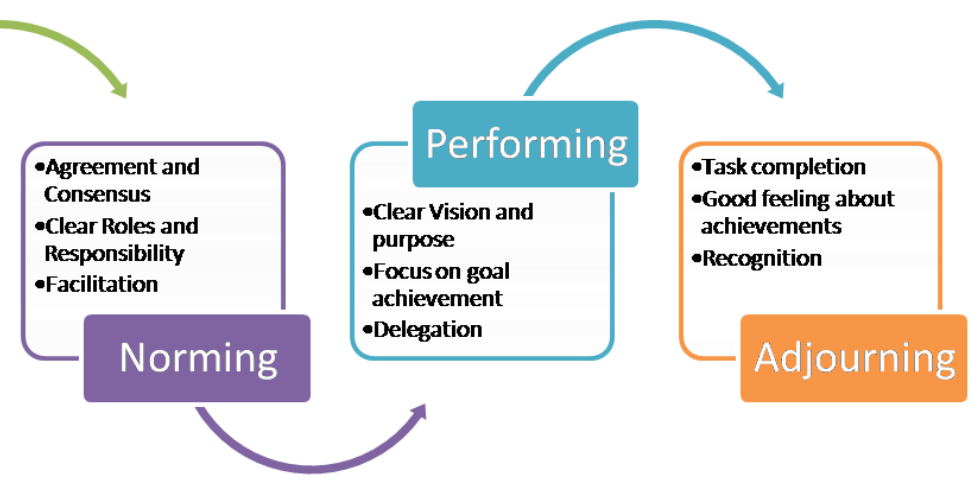

Scherrer, Olcoń, Butterfield, and Kebede (2016) summarize the five stages of group development by stating the following:

Five stages of group development [consist of] forming, storming, norming, performing, and adjourning $[\ldots]$ Forming is seen as a period for the establishment of interdependency between the members of the group and on the group itself. During storming, the leadership of the group is established and roles within the group [are] assigned to group members, which establishes cohesion. In norming, the cohesive group determines the rules for its functioning. [The] performing stage has the structure to work on completion of the tasks assigned to it and to produce a tangible result. The final stage, adjourning, permits the group to review its work (p. 697-698). 


\section{Title IX and Inequity}

The USA women's national soccer team has been actively fighting for equality with their male counterparts for decades. According to Das (2019), "The discrimination, the athletes said, affects not only their paychecks but also where they play and how often, how they train, the medical treatment and coaching they receive, and even how they travel to matches" (para 3). It is interesting to note that the discrimination happening at the professional level also happens at the collegiate level. Ross (2015) states, "Aside from tennis, women's athletics are widely viewed as an inferior product among the country's main sports and thus often disregarded. Even curating data on women's sports is almost impossible because it's practically nonexistent" (para 2). Consequently, Title IX was created. According to Jackson (2014), "Title IX of the Education Amendments Act of 1972 is a federal law that states: 'No person in the United States shall, on the basis of sex, be excluded from participation in, be denied the benefits of, or be subjected to discrimination under any education program or activity receiving Federal financial assistance'" (para 1). Title IX was created to prevent discriminative behaviors towards females in academic settings. However, research shows that "general campus-wide training initiatives, which include education on the Title IX requirements, do not necessarily increase the likelihood of complying with mandated reporting" (Newins, Bernstein, Peterson, Waldron, \& White, 2018, p. 17). Unfortunately, there are still plenty of violations, one of which is sexual harassment, of Title IX on university campuses nationwide. Although certain training is implemented, university employees and students still express a lack of mandated reporting. Therefore, "the spirit and intention of the Title IX reporting requirements are broadly considered a step toward the goal of decreasing incidents of sexual aggression and harassment on college campuses," but results show 
that there is still an ongoing issue with gender discrimination and sexual harassment in higher education (Newins et al., 2018, p. 17). 


\section{CHAPTER 3}

\section{METHODOLOGY}

\section{Research Design}

The data collected was completed through ethnographic observation of the Andrews University Lady Cardinals soccer team. According to Bubpa and Nuntaboot (2017), Ethnographic (2017), "Data [can be] collected through observations, in-depth interviews, focus group discussions, and by analyzing available documents which were from the area studied" (p. 367). In this study, data were collected through observations made at soccer matches and trainings, as well as other miscellaneous settings where the team was together such as restaurants and transportation vehicles. Observation charts were developed which allowed me to document how individuals who formed part of the team (both players and coaches) interacted with one another. Through daily observation, experiences and interactions were documented with the purpose of demonstrating the duration and completion of the different group stages of development and the progression of relationships within the team through Tuckman's theory. Two concepts evaluated include conflict resolution and communication which are both an integrative part of group dynamics. Both of these were studied through participant observation and post-season interviews. The interviews conducted were beneficial to obtain information through participants' experiences personally mentioned through rich description. Out of the 16 players, I interviewed 15 of them. I also interviewed one coach through face-to-face communication, and I received interview responses from two other coaches via email. Only one of the four coaches chose not to participate in the interview process. The interviews varied in 
length from the longest one being approximately 51 minutes to the shortest one being approximately 21 minutes. Interviews were then transcribed and analyzed for different themes. Interview answers were expected to correlate with data collected through observation.

One of the things that makes an ethnographic study valid is the concept of analyzing and studying a group in which one is actively present. For example, in the study done by Bubpa and Nuntaboot (2017), "the researchers spent 1 year and 3 months studying the elderly group" which implies that there was a relationship established throughout the duration of the study. As for me, some of the soccer players this year were returning players that I have known prior to the start of the 2018 season. In order to conduct a valid study, I formed new relationships with the players who were joining the team for the first time this season of 2018. Also, the concept of time, meaning the duration of the study, was a period of 15 weeks. Interpersonal relationships are expected to develop over a period of time. Therefore, according to Tuckman's theory, there is some sort of progression and retrogression that results in team formation. It was interesting to see the team fall into the different stages of this model.

The use of the ethnographic method for this specific study provided me with a clear insight into the experiences of participants of the Andrews University soccer team. There is a difference also in simply having answers to interview questions rather than having those same answers and matching them to real-life experiences both I, as an ethnographer, and the participants have seen, felt, and been an active part of. Also, the observations made on a daily basis during the duration of the study provide more accurate data rather than having a questionnaire where no richness can be seen, nor expressed, nor proven. Yet, as an ethnographic researcher who is an active part of the team, I was able to witness the reality of the interviewees' answers. 


\section{Participants}

The participants of the study were female students who signed up to be on the soccer team and who agreed to be a part of the study. There was no specific recruitment done on my part besides sharing the attached flyer (See Appendix A). The flyer was created by one of the four soccer coaches for the season of 2018. Furthermore, the sample used was a convenient sample of anyone who decided to willingly participate in the 2018 season as a member of the soccer team. The only criterion was for the participant to be an active female player on the team. Due to the amount of fallout (players leaving the team) early on in the season, additional regulation was made. In order to be included in the study, participants had to attend at least 40 percent of the official matches (approximately four out of nine games) and $80 \%$ of practices sessions.

I studied the group dynamics of the team which consisted of four coaches and 16 players. Originally, there were 20 players, but four of them left the team at different stages of group development. I studied the group for approximately 14 weeks. Data was also collected through post-season interviews which were conducted after the last game of the season (October 21, 2018). The first interviews were conducted on October 28, 2018; interviews varied in length depending on the depth of the answers the participants provided. The longest interview was approximately 51 minutes long whilst the shortest was about 21 minutes. I interviewed 15 out of the 16 players on the women's soccer team as well as three out of the four coaches for the 2018 season. All the interviews were conducted face-to-face except two (two coaches responded to interview questions via email.) The interviews consisted of 17 questions that were formulated as the season progressed. 


\section{Instrumentation}

The instrumentation used for this study consisted of multiple charts (See Appendix D). Because the study was conducted as an ethnography, the main form of data collection was completed through observation. Approximately 14 weeks of data were collected starting on July 23, 2018, and ending on October 21, 2018. However, it was imperative that data be documented accurately and specifically on a daily basis. This was done to ensure the best understanding of the different moments in which the team entered a new stage of group development in accordance with Tuckman's theory. In order to assess the study's hypotheses, I collected and kept track of concise data using two main charts: Daily Observation and Minutes Played. The daily observation chart focused on conflict resolution, relationship development, skills practiced and developed, and communication (inclusive/exclusive; positive/negative). The Minutes Played chart referred to the number of minutes each participant played during the 2018 season (11 games; two canceled; nine games played in total). Therefore, each player had a total amount of minutes at the end of the last game on October 21, 2018. This number was used in correlation to participants' skill level and level of morale. Therefore, I used the Minutes Played chart to see which players played the most and the least during the season to answer the research question, how does the number of match-minutes played affect team members' morale/team spirit?

The subjects who participated were not exposed to any more risk than they would be in a normal soccer season. There was always the risk of an injury, however, an injury would be the result of playing the sport itself and not a result of participating in this research. Subject confidentiality was kept under all circumstances for all the players and the coaches. Additionally, a coding system was used so that no names will be included when describing participant behavior/communication in regard to stage development and areas targeted for research 
questions/hypotheses. I assigned all the players a number that is not according to their jersey number. Only I have access to this list of players and their assigned numbers.

I was not given the second-year assistant coach position for the team being studied, nor was I able to actively participate as a player during the season due to NCAA regulation, thus I was able to preserve research validity. I had absolutely no contributions in regard to choosing which players played in official games and the number of minutes each member played. I was able to better observe the subjects after establishing and maintaining relationships with them during the soccer season. I wanted to conduct this research because I personally wanted to see what measures could be taken to improve the overall performance and success of the Andrews University Lady Cardinals soccer team through the study of group dynamics and group development stages. Therefore, there was no interference on my behalf since my purpose was to gather the most accurate results I could in order to understand what areas could be improved to ensure the success of not only this season's soccer team but the success of future Lady Cardinal soccer teams.

After completing the interview process, I translated the interviews online using the website otranscribe.com. Once I had all the transcriptions, I used the software NVIVO to organize the various themes found in the interviews in order to analyze the information obtained. 


\section{CHAPTER 4}

\section{FINDINGS AND DISCUSSION}

I collected data throughout the 2018 soccer season. I took daily observations for approximately 98 days. I conducted interviews that accumulated to approximately 624 hours of face-to-face communication with the players and coaches.

\section{Group Dynamics}

\section{Succeeding Factors}

During the interview analysis, three central factors were discovered that aided the success of the Andrews University Lady Cardinals soccer team: Positive Attitude, Unity, and Support.

Figure 2 Factors That Helped the Andrews University Lady Cardinals Succeed According to Interview Responses

\section{The Team Perspective: Succeeding Factors}

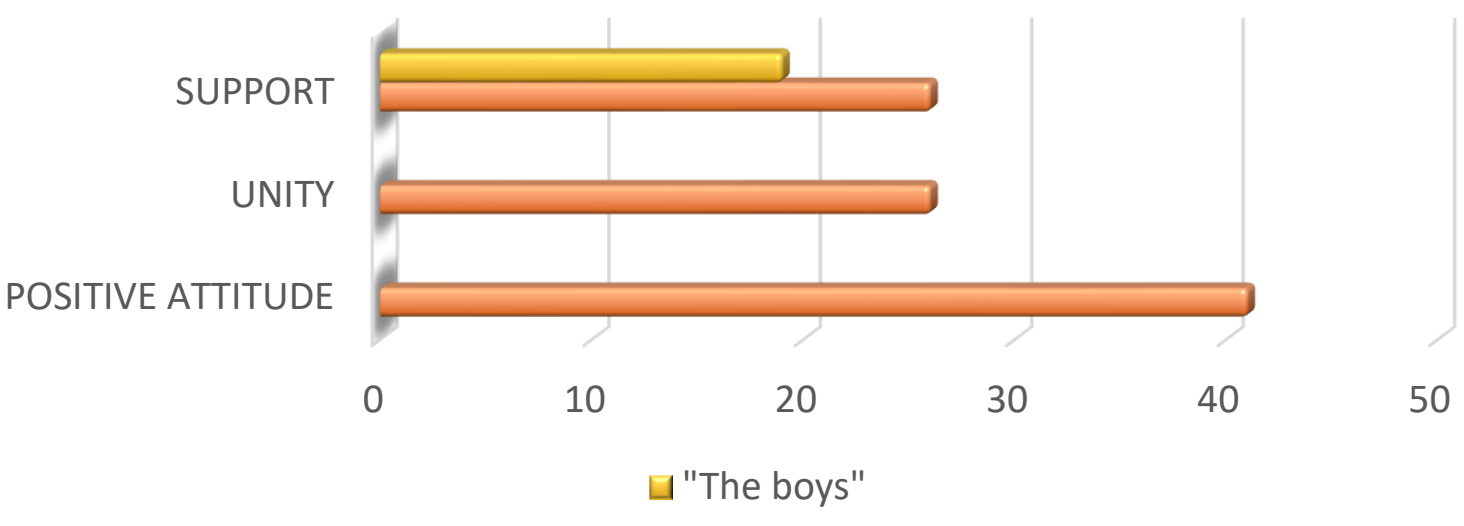

As shown in Figure 2, there were 41 times where the coaching staff and players 
mentioned that keeping a positive attitude played an important role in the success of the team. There were multiple instances where players provided examples of positivity and encouragement they experienced during the season. This correlates with the factor of unity which also helped the success of the team. In having positive interactions with each other, the players explained that the levels of inclusion of the team were very high which made them feel like they could work together to accomplish their goals. According to returning players, this season's team was more inclusive and united than teams in the past. This is true according to player \#6 who stated, "I think the team was actually more of a team this year than last year."

Lastly, support was a key factor in the success of the group. Support encompassed the support from Andrews University Athletics and other people, or "fans", that would come to cheer on the team during official matches. The players stated in the interviews that they really valued the support because it would push them to work harder and it would make them feel like they could win. Some players specifically mentioned the support from the Cardinal men. For example, one of the captains, player \#2, stated:
Also having the guys from the men's team come helped too. For sure. Especially that last game when they were like right on the sidelines and as I had the ball, they were giving me like advice on what to do. That's was really helpful, and I felt like they were really invested in the game and that was like more motivation to do better.
The term the boys was mentioned to describe the players who belonged to the Andrews University Cardinal Men's team and appeared in interview answers as a helping factor a total of 19 times. It is evident that the team valued the Cardinal men. Player \#14 described her experience with one of the Cardinal men in particular: 
The boys were super supportive, who even after our losses would come and tell us we played a good game. That was really encouraging because the boys are such a good team themselves, and as individual players, it's really nice to hear that coming from them. They're playing these teams too and they know they are hard too, so it's nice to hear it from them. I look up to them because they are so good. I didn't even know [one of the players] at the time, but he came to watch, and I think after the third game or something he was like, "Oh my gosh, you're doing really good." And I was like “wow”... because I watched him, and I was like he's so good and he said I was good! I was literally like in shock. He was really encouraging and really great. And that's something that stuck out to me because just for someone of his skill to say that to me was really cool.

In previous years, there was not plenty of support from the Cardinal men, so it was interesting to take note of how much the support this year meant to the women this year.

\section{Players Valued by Coach and Team Members}

During the season there were players who were valued by the coach and fellow team members. According to both observations and the interviews, it is evident that the coach showed favoritism towards the captains. When posed with the interview question, "Are there certain players that you believe were more valued by the coach in comparison to others?" the word captain(s) was mentioned 17 times. Both player \#2 and player \#5 were captains this season. Although one player was specifically named out of the two captains, for anonymity, together their names were mentioned a total of 41 times. One of these players was preferred by the coach because of administrative reasons because she had exceptional leadership skills despite her young age. This player also stated: 
I expected more organization... more commitment. It just kind of seemed like somewhat like intramurals to me because it was really just all over the place. And from what I know like that I have seen other schools were just really organized, and I don't know why, but like I have this thing like this urge to help especially if no one is like stepping up to help out. So, I guess that is why I took it upon myself to just help out because I was like I have to do something about it and in that sense it wasn't at all what I expected. Especially being a freshman and all, I just thought I was going to be like the newbie and sit back and learn, but because of how everything was going, like... I kind of immediately stepped up in a position of leadership... especially being captain like that was just thrown out there.

This affected group dynamics because although the group of players was very close-knit, during the interview, some players voiced their opinion on the coach's favoritism. Player \#11 stated, "Like sometimes in practice I would come late. And I still would have to do like four laps or something and when she would come late, she would have to do maybe like one or two and then she was ready to [play]." Multiple players had similar experiences like this where they perceived a level of unfairness. Even so, no player expressed ill feelings towards this favored player. In fact, everyone on the team valued and appreciated everything that this player did for the team. The team concurred that if this player did not step up and accept responsibility for certain things, then no one else would. Player \#4 described the situation as follows:

Everything was all over the place. [She] did such a great job for what she did, but it wasn't right because she wasn't getting paid for it and she would be like, "oh it's okay," but it was really not okay. And like she's a freshman. A lot of the things she did, I feel like she was taken advantage of, I think she was exploited because she was trying to be a good person. She would always say things like, "if I don't do this, then no one else is going to do this" 
and that's not the right attitude. Like she had school and she had other stuff to do. This is not her responsibility, like if she was getting paid for it then it would've been a different story.

From a coaching staff perspective, one coach stated, "[she was valued] by the coaching staff. I guess from an organizational perspective because she helped with paperwork and things like that. So, the staff valued her definitely more because we needed her to accomplish a lot of things" Therefore, this valued player was also part of the organizational structure of the team itself.

The team also valued certain players over others, yet the concept of unity was the overriding theme that arose not only in response to this specific question but in response to all interview questions where they had to speak about the team itself. It was sometimes difficult for players to not name the entire team for the question, "Are there certain players that you believe were more valued by the team in comparison to others?" In fact, there was never one time where only one player was mentioned for that question. Respondents would continue talking about what each player was good at and would sometimes forget the question altogether. They had/have genuine friendships as expressed during interviews as well. This was evident to coach \#1 when during the interview they stated, "honestly, like when it came to the players, they just valued the heck out of each other" Also, to player \#13 when she said, "I feel like when it comes to the team, we all were very appreciative of everyone." The number of positive responses in regard to the way the players viewed each other even in light of this question is immense and further discussed in the Inclusive Communication Vs. Exclusive Communication section. One comment that paints a picture of the overall relational dynamics of the players is the following stated by player \#14: 
I loved all the girls on the team. Literally, they're all my really good friends. I love them so much. I had such a great time with them. We play for each other and we worked really hard. I really appreciate that. I loved away games. I loved our bus parties. Eating out with the team. I loved the team. The scheduling could've been better, but overall I loved the season. I found a group of girls that I have formed special lifelong friendships with so that was really important for me.

Therefore, there was a variety of specific player names mentioned who were perceived as valued by the team, but in the end, most players responding would specify that the team valued everyone and appreciated everyone. The names of players who were valued almost covered all the players on the team. In other words, almost everyone's name was mentioned at least once for this specific question of players valued by the team.

\section{Decision Participation}

When asked, "who participates when decisions are made?" the majority of respondents answered coaching staff. Head coach/Assistant coaches were mentioned 13 times. The player that was favored by the coach was mentioned 11 times; team only three times and Athletic Director once. According to one of the coaches who experienced soccer as a career, communication between coaching staff and players should have been different. They stated:

More of a professional aspect of communication because we were so relational that a lot of times it felt like we were just a bunch of buddies. Friends on Facebook talking. Like you need to be professional with your team. You know? Like if you're going to communicate with everybody, then send an email or however way the team better communicates, but there should be boundaries. When the coach says you jump, you jump. You don't ask anything, you just jump because the coach is telling you to do it and you have to believe 
them at the end of the day, A lot of times things would just be suggested, and there would be a conversation about things that I don't think should be a conversation within the soccer structure. Like whatever the heck coach says, goes. You might not agree with it, but that's the way that it happens. And sometimes the players, not all the time, depending on what it was. It would depend on the situation, [the players were allowed] to make smaller decisions as far as practice, a few dynamics of practice, but team organization, and short term, long term goals it was just [the coaching staff].

According to interview responses and observations, players viewed the coaching staff as the ultimate voice for decisions. However, some players were not accustomed to the soccer culture of a more professional team organization. Therefore, they had a different view of the coaching staff, the coach, in particular, making the decisions. Some players found it to be off-putting that the coach would not listen to their opinions or what they had to say. When asked about who participates in decisions, player \#15 responded:

I feel like there is not a lot of team participation, but it is not because we don't want to be involved. We're not given an option usually, so like if we find things out, it is usually like last minute or it's an executive decision that has been made of run through maybe one of the captains if we're lucky, but most of the time it is just the executive, like not including the team. Or if the coach wants, sometimes he will ask us for our opinion and end up doing just like whatever he wants.

Player \#9 stated, "[Coach] definitely because I feel like... yeah, I don't really feel like we have that much of a say when it comes to the way that we play the games or practices or anything. Honestly, I mean we can make we make some decisions for ourselves, but most of it is control." It is evident that there was a lack of communication between coaching staff and players when it 
comes to the understanding of organizational structure of the team. Evidence of this can be found in the Ineffective Communication in Leadership section. Although the player that was favored by the coach was mentioned 11 times, the coaching staff had the ultimate decision when specific situations arose and on a regular day-to-day basis according to interviews and observations. When this player was posed the same question, she stated, "Coach and assistant coaches mainly", but after some thought, she continued with, "I guess with the coach and I... I somewhat ended up working for him..? So, like just time, scheduling, preparation, sending texts and things like that since I guess I did make decisions too." Therefore, it is evident that this player also played a role in the organizational structure of the team including making certain decisions.

\section{Inclusive Communication Versus Exclusive Communication}

Figure 3 Interview Results of Inclusive and Exclusive Communication Instances During the 2018 Soccer Season

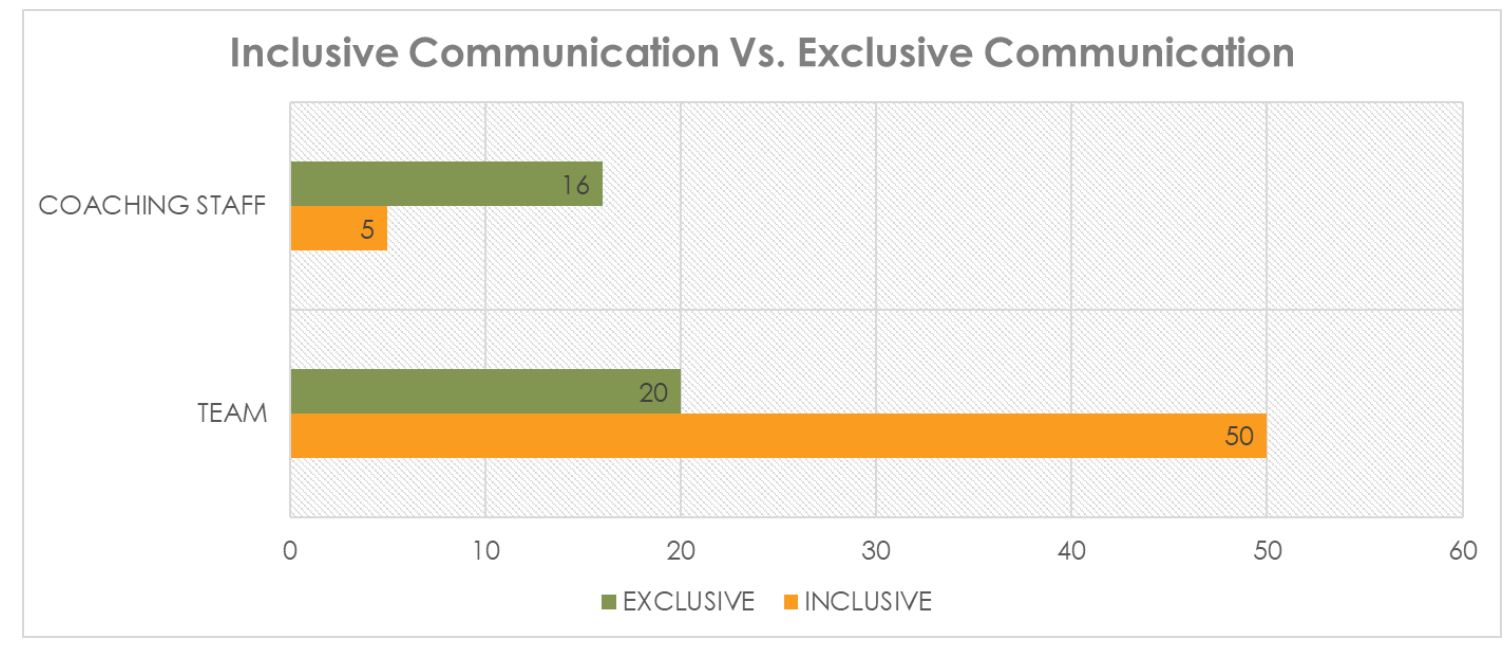

During the season, the players experienced both inclusive and exclusive communication. Players experienced different situations which they perceived as inclusive or exclusive in different interactions with other team members and with the coaching staff (see Figure 3 ). The most inclusive communication moments were experienced amongst the players themselves in 
feeling like they belonged to a group of women who were positive and encouraging whilst trying to achieve a goal. For this reason, the mentioning of team/players is the greatest among the responses to the inquiry, "What are some things that you would hear during the season that were positive and negative?" in light of inclusive communication versus exclusive communication. The positive concept of team/player was mentioned a total of 50 times throughout the interviews by both players and staff. The word inclusion in its different variations (included, include) was mentioned 24 times. The following are examples of inclusion retrieved from the interviews:

Player \#15: "I love these girls. We've been through a lot together.."

Player \#12: "The team would mostly say positive things like you did good.. and stuff like that. I felt included."

Player \#9: "I'm really glad I joined because it helps. It helps me as a transfer student make a lot of friends that I wouldn't otherwise. It made me feel included and I really appreciate all the girls on the team. I Feel like I mean personally it was really valuable like being able to be part of something."

Player \#10: "I think the team overall was pretty inclusive."

Player \#14: "Honestly, during soccer, we didn't really break into our cliques or groups we tried to work as one because I mean... I noticed it on soccer teams in the past it can get cliquey, but that's not the case for us. Like I like hanging out with everyone. They're all my sisters." These are some examples of some players expressing in their own words their experiences regarding team inclusion. It is evident that the Andrews University Lady Cardinals has trouble recruiting players as discussed in section Preseason: Tuckman's Theory. Also discussed in the Post-season Improvements section, the concept of team promotion as it is also true that the team does not have a good promotion which is one of the reasons why players are accepted into the 
team way past the first game. This affects the group dynamics regarding inclusion because it gives an opportunity for those new players to experience feelings of exclusion. Player \#16, for example, stated, “Um... I think that I didn't know the rules very well or the girls because I missed the very short preseason we had. I didn't know how to communicate with them until around the final game. My communication was very distanced. I felt like I wasn't really in the group.. sometimes it was frustrating because I didn't know them. I just went there just trying to do my best." In validation to this player's feelings, coach \#1 had this response about the way they viewed inclusion on the team, "the players that were really new, they had a hard time sometimes integrating with the team just because they didn't have the soccer lingo to connect with the group.” In this case, organization plays a role in the exclusion experience of player \#16 because part of organization is the communication that is established between coaching staff and players especially in dissecting rules and expectations. One of the captains explained this about another late player who was not specifically included in the study due to not meeting the requirements. Player \#5 stated," I think she ended up not coming back probably because she didn't get enough playing time and because in practices because we were like so far ahead like she joined in the middle of the season. Everyone was so far ahead, so I guess she was just really confused, and no one had really broken it down for her." Player \#16 continues expressing her feelings by saying, "When I first got to the team, we had to have a partner to pass the ball. I had no partner, so the first 3 times I went there to practice... girls started to avoid me because they knew who played well like among them because they knew each other, so they were choosing each other, and I was left out." In contrast, player \#1 who was integrated late, but not as late as player \# 16, had this experience: 
I was a late player. I think coming in late affected my relationship with the girls a little bit, but I transitioned into being like one of them fairly quickly which was really nice, but maybe just a little. I think that when I first was introduced to each team member when I came, they were really friendly. And we were doing like our warm-up laps and pretty much everyone said hello to me like what are you studying and things like that. I enjoyed coming to practice and just being around the girls

Due to the nature of this qualitative study, it is normal for there to be a variety of experiences and each one of them is valid. Even though player \#16 felt moments of exclusion on the team, according to her, most of them were experienced only in the beginning of her time with the players. When asked to share any additional comments, player \#16 declared, "I made real friends. Even now when I'm around and they see me, they will come and hug me and ask me how I'm doing. I openly talk to them as a friend. Teammates are better than classmates. The girls really want to get to know each other."

Furthermore, all of the 20 examples of negative communication that aided in feelings of discouragement and exclusion were experienced at the beginning of the season when the players were just getting to come together and know each other. This tension to be expected in the early stages of group development and is further discussed in the section entitled Tuckman's Theory. Most occurrences of exclusive communication happened during games under an elevated level of frustration. Player \#2 described these negative experiences when she said, "I felt it like in the beginning, maybe because we weren't used to playing or because we didn't have that much practice, but I felt like in the beginning there was some yelling especially after goals were scored on us." This encompasses the rest of the team's thoughts when describing negative moments between the players themselves in general. 
Nevertheless, it is interesting that most feelings of exclusion were found to be experienced in interactions between the players and two of the coaches, coach \#3 and coach \#4. "The thing that killed it for me the most was [coach \#3] making me feel like I shouldn't be on the team basically" stated player $\# 8$ when asked to share her experiences of exclusion on the team Also, player \#7 stated this about coach \#3, "Sometimes [they] would like especially encourage certain girls, but then [they] would tell other girls like, 'you know what we're going to work on.' And even like if it was a good game, like a game that we won, [they] would say stuff like that which I don't think is fair because it's a group contribution." In correlation to this player's observation, player \#14 described her experience as the following:

Also, [coach \#3] would always tell me what I was doing wrong and not ever really what I was doing right and that made me feel excluded. Like the game that we won all [they] had to say to me was something negative because I missed a breakaway which I know I need to do that better. I know what I did wrong and stuff like that, but all [they] said to me was, “I guess we're going to have to work on that aren't we?" And I was like man that's not really what I want to hear after we just won. Maybe say, "good job" and then say hey maybe we can work on this. You know? Better way of saying it. That kind of made me feel excluded because I thought I had a good game.

Unfortunately, this was not the only observation of exclusion involving coach \#3. Player \#14 continued by stating, "During practices [coach \#3] would pick on people... especially the last week like every practice one person or a couple of people. It makes you feel excluded. It makes you feel like you're not a part of the team if [one of the coaches] is treating you that way. It makes you feel like you're not part of what we're doing." Player \#4 inadvertently validated player \#14's experience with coach \#3 when player\#4 stated, "Also, when [coach \#3] was not 
encouraging to the players like especially after they had a hard game, that really brought their whole morale down. Like what is the point of me being on a team if [one of the coaches] can't even be nice to us, or [...] can't even help us. Like you feel really helpless you know.”

Coach \#4 also made the players feel excluded and unmotivated according to player \#4 and player \#11. According to both players, coach \#4 would say negative things on the sidelines during games and during practices. Player \#11 stated:

As for exclusive things, I would hear... [coach \#4] like [they] would just make negative comments about us not being I guess fast learners or as good as [they] expected us to be so that just made us feel like we weren't going to do good. Like that would bring our attitude down... sometimes in practice when we would hear stuff like that. Yeah. The practice was kind of just done for the day like it wasn't fun.. we didn't even want to be there just. It kind of just took our motivation away.

This was one of the descriptions of what happened during practices. Player \#4 expressed a similar situation in a different setting: during the games on the sidelines. She stated:

Also, this really really really made me angry, but for at least three of the home games that we had, um... we had [coach \#1], we had [coach \#4], and we had [coach \#2], and [coach \#3] on the sidelines. And we're there, we're pumped up, we're doing our best. And when I was subbed or I was off the field, I would hear [coach \#4] and [they] would be like, "Oh my goodness. Ugh. If this was a real game, that would never have gone through" or like, "if this was a real game, that wouldn't have worked" or whatever. And such negativity like [they] would be like, "Oh my goodness, like these girls can't even. [...]” It was so negative, I literally looked at [them] and rolled my eyes, and I just walked all the way to the other side opposite to [them] because I was like, I don't want to hear this. Like it's one thing if 
[they] would've been like, “Aw, she could've done that," but no. It was purely like "oh my goodness, this team is so hopeless." Just so negative. And it wasn't just one game. It was literally every game [they were there]. Like I would have to move physically to the other side because I couldn't handle [their] negativity. Even when we were winning, [they] would yell at us.

Even though the players expressed these exclusive moments that caused negative emotions to arise, they did not all experience these situations with coach \#1 or coach \#2. In fact, the players expressed positive experiences they had with coach \#1. Several accounts from different players describe a different, more positive scene during games. Player \#5 stated this regarding her experience with coach \#1:

Like during the games like on the sideline or something, [their] voice would be the one I would hear the most. And I think there was one time where it was like half-time or something. And the first half, I just wasn't feeling it and so during half-time, [they] talked to us, [they were] like, "give it your 100 percent even when you are running, don't just be walking around." And the second half started and like I started to run a whole lot faster and I started giving it my like my 120, 150 percent. And I could just hear [their] voice on the sideline like, "keep going! keep going! keep going!" and that was really great. I found that really positive and encouraging.

Player \#14 described a similar experience stating:

I know we had a game I think against Lincoln, and me and [player 1] were on the side... and all I heard was [coach \#1] yelling out, "Pass it Pass it," and stuff like that. That was really encouraging and positive because afterwards [they were] like really good job guys. 
We didn't score or anything or do much with it, but it was still positive, and I felt we did really good with that. So just like those little things made me feel included.

It is evident that coach \#1 had a positive impact on the way the players experienced playing on the team in making sure to be encouraging during the games. Furthermore, I also observed these examples throughout the season involving positive interactions between the players and coach \#1. I enjoyed interviewing coach \#1 because they provided further insight as to their intentional approach to coaching especially when dealing with a very diverse group of women both in cultures and in levels of soccer experience as shown in Figure 4.

Figure 4 Player Profile Summary for the 2018 Soccer Season

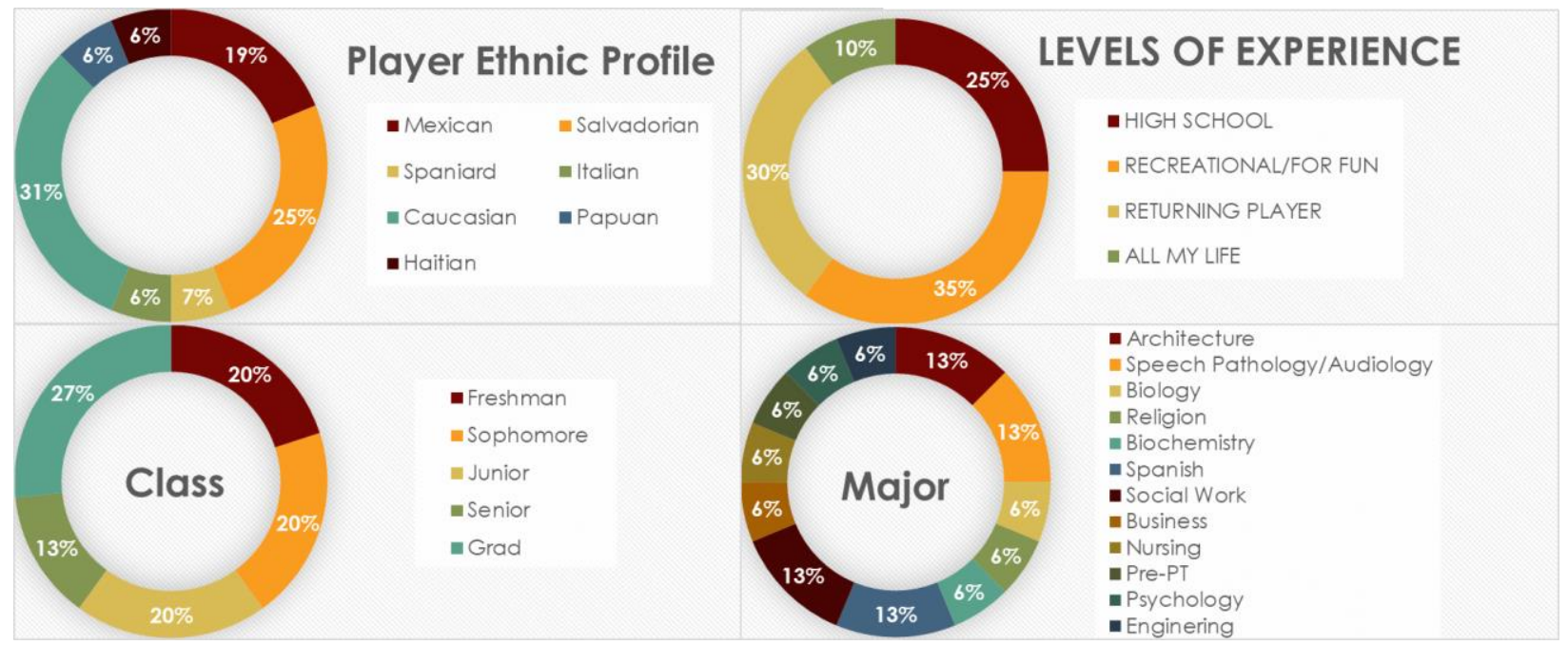

It is obvious that coaching is more than showing up to practices and games. Coach \#1 demonstrated throughout the whole interview that they understood this to be true. When asked about inclusion versus exclusion, they stated:

There were several times when I knew that the skill level of one player was so much higher and more developed than the other that the less developed player was not going to understand what we were talking about. But nevertheless, I couldn't leave them out because 
then they wouldn't feel like part of the process. Especially with the keepers. We had keepers that had never played keeper never in their lives. Then you had a keeper who had played for several years. So, there were several times, I could say easily 50 percent of my time with them was spent just allowing them to feel comfortable. I'm trying to teach one keeper the techniques and I'm allowing the other keeper to just feel comfortable being called a keeper, being part of the conversation even though they're not going to get any of the tactics. Just completely different levels like they would not be on the same field, but to me, it was more of a mental thing where if they felt like they belonged, they would put in effort to try things out that they would probably never do if I had required of them in a more advanced and more professional sort of way where I separated them into two camps, and I said, "you know you are the advanced keeper, let's work on these things. You are not the advanced keeper, I'm going to work on very basic things with you." I did those things, but I worked with them together, so that nobody would feel left out.

Therefore, although there were some negative exclusive experiences during the season, according to the players, they were mostly interactions with coach \#4 and coach \#3. However, the coaching staff as a whole was a group of four different individuals with different personalities, skills, and abilities. The team itself expressed favoritism towards one of the coaches in general: coach \#1. It is understandable the players enjoy working alongside this coach when obtaining coach \#1's approach to the concept of inclusion and what it meant to him to include the players in feeling like they were part of the process of learning together. The negative communication that made players feel excluded that emerged during the intensity of official matches was more concentrated at the beginning of the season when the team was starting to grow interpersonally. Regardless, these moments of tension did not deter the team from staying 
positive and building each other up, not only as teammates but as friends. Player \#4, a returning player, concluded:

I was so blessed to be with the girls every single day. Last year I felt super disconnected from the team. There were so many cliques, and I felt like I didn't belong, and I really didn't like it all that much like yeah, there were some nice aspects, but this year, all the girls were so hard working that it pushed me to really want to do my best. I've never run like this; the way I ran with them. Like that's not me though, that's God and also the girls because they are such an inspiration for me. And I tell them that they inspire me every single day.

\section{Match Minutes Played}

Throughout the season, it was enjoyable to spend time with the Andrews University Lady Cardinals soccer team. Due to the ethnographic nature of my study, I was able to enjoy my time with the players and the coaching staff whilst simultaneously recording and documenting my observations. In order to accurately answer the research question, "How does the number of match-minutes played affect team members' morale/team spirit?" I attended all the home games at Andrews University as well as accompanied the team on its trips to away games.

\section{Table 1}


Total Number of Minutes Each Woman Played for the 2018 Soccer Season

\begin{tabular}{|c|c|c|c|c|c|c|c|c|c|c|c|c|c|c|}
\hline Player \& game & 1 & 2 & 3 & 4 & 5 & 6 & 7 & 8 & 9 & 10 & 11 & $\begin{array}{c}\text { Total min. } \\
\text { played } \\
\text { (season) }\end{array}$ & & \\
\hline$\# 1$ & & & & 45 & 81 & 31 & \begin{tabular}{l|l}
43 & 9 \\
\end{tabular} & 90 & 0 & 90 & 76 & 456 & & \\
\hline \#2 & 90 & 70 & & 81 & 90 & 0 & 909 & 90 & 0 & 90 & 90 & 691 & & \\
\hline$\# \mathbf{3}$ & 84 & 70 & & 90 & 90 & 90 & 909 & 90 & 0 & 90 & 0 & 694 & Legend: & \\
\hline$\# 4$ & 69 & 0 & & 36 & 5 & 90 & \begin{tabular}{l|l}
90 & 5 \\
\end{tabular} & 55 & 0 & 55 & 24 & 423 & Ineligible & \\
\hline$\# 5$ & 90 & 70 & & 90 & 90 & 90 & 689 & 90 & 0 & 90 & 90 & 768 & Not part of & \\
\hline \#6 & & 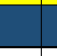 & & & 48 & 90 & $74 \sqrt{9}$ & 90 & 0 & 90 & 78 & 470 & the team yet & \\
\hline$\# 7$ & 90 & 70 & & \begin{tabular}{|l|l}
76 \\
\end{tabular} & 90 & 0 & 909 & 90 & 0 & 90 & 90 & 686 & Absent & 0 \\
\hline$\# 8$ & 16 & 70 & 0 & \begin{tabular}{l|l}
0 & 0 \\
\end{tabular} & 6 & 0 & \begin{tabular}{l|l}
16 & 1 \\
\end{tabular} & 12 & 0 & 12 & 0 & 132 & & \\
\hline \#9 & & & & 45 & 78 & 0 & 908 & 81 & 0 & 81 & 90 & 465 & & \\
\hline$\# 10$ & & & & & 90 & 90 & \begin{tabular}{l|l}
90 & 9 \\
\end{tabular} & 90 & 0 & 90 & 0 & 450 & & \\
\hline \#11 & 78 & 70 & 0 & 090 & 90 & 90 & 90 & 0 & 0 & 90 & 90 & 688 & & \\
\hline$\# 12$ & & & & 78 & 60 & 90 & \begin{tabular}{l|l}
73 & 8 \\
\end{tabular} & 83 & 0 & 83 & 83 & 550 & & \\
\hline \#13 & 54 & 70 & 0 & 090 & 55 & 0 & \begin{tabular}{l|l}
65 & 5 \\
\end{tabular} & 56 & 0 & 56 & 90 & 536 & & \\
\hline \#14 & 87 & 55 & & 090 & 90 & 90 & \begin{tabular}{l|l}
90 & 9 \\
\end{tabular} & 90 & 0 & 90 & 90 & 772 & & \\
\hline \#15 & 90 & 70 & & 090 & 90 & 0 & 0 & 0 & 0 & 0 & 45 & 385 & & \\
\hline \#16 & & & & & & & & 0 & 0 & 0 & 21 & 21 & & \\
\hline & & & $\begin{array}{l}\text { Game } \\
\text { canceled }\end{array}$ & & & & & & \begin{tabular}{l|} 
Game \\
canceled
\end{tabular} & & & & & \\
\hline
\end{tabular}

As shown in Table 1, each player spent a different total of minutes on the field from the first match of the season on September 2, 2018, to the last match of the season on October 21, 2018. The highlighted rows are the most significant players that stand out for a reason. Player \#5 and player \#2 were the captains of the team and they played a large amount of time in comparison to other players. Although player \#3 played 694 minutes, three minutes more than player \#2, in the whole season. This player had never been on the soccer team in the past, yet she was voted the most improved for the 2018 Lady Cardinals' soccer season. Unfortunately, this player was unable to participate in the post-season interview due to a conflict of schedule.

However, she was observed to improve greatly when comparing primary and final meetings with the team. It is evident that one factor, in particular, played a vital role in this player's improvement of performance: the number of match minutes played. 
According to player \#14:

Like that girl played every minute. She was a captain so clearly, he would try to facilitate her to get to the team, but I felt like there was a lot of favoritism. With the playing time for sure because there was one week when someone had been there all week when [player \#5] had missed practice that week and while she played the whole 90, they were sitting bench. If the game was close and she was the better option, then, of course, keep her in for the rest of the game, but we were already losing so it was like give that other player who put in the hard work the opportunity. I've always believed that if you're putting in hard work, you should get the reward.

Clearly, player \#14 did not state this for her own benefit because she actually played just about the same amount as player \#5; she had 772 minutes total while player \#5 had 768 minutes. In fact, player \#14 is one of two players on the team who, according to her interview answers, has played soccer most of her life. Therefore, it is apparent that the coaching staff also valued her because of her skill level according to the number of minutes she played. Player \#14 described her experience regarding the games stating, "I really liked the season honestly. I love all the friends I made. Of course, games too, but we play for each other and we worked really hard. I really appreciate that. I loved away games." This player had high morale. She was motivated and excited for not only games, but also practices, and spending time with the team in general as described in different interview answers. In comparison, player \#8 did not have the best experience at games either at home or away. In fact, out of everyone, besides player \#16 who only played one game due to coming in late, player $\# 8$ played the least amount of minutes even though she was present six out of the nine games. This is what player $\# 8$ had to say about her experience playing official matches and how it affected her morale at the end of the day: 
I feel like in practices and stuff, we all played together, and it was fun, but then when it came to the games, it's like I couldn't really like relate because I didn't play you know? That affected like how I felt on the team and it really made me not want to join next year. Because it just seemed pointless. It seemed like kind of a waste of time if you're there to play, you're there to learn, you're there for that specific reason. But I just feel like [one of the coaches] didn't value me as a player. I feel like [they] only valued me when there weren't enough girls. And then I was important to [that coach]. But any time the whole team was there, I only played like a minute or two. Like I was never playing. And at that point, I was like why? Like I don't even know why I'm here like. And that is why I would not join again like... If I am not going to play, being there for two hours like every day for practice and the games and not playing. It's just not worth it.

Due to the lack of time spent alongside team members on the field during matches, player \#8 felt feelings of exclusion and a lowered morale overall. She felt that it was unfair to come to practices and not get to play in the official matches. Unfortunately, even though it is clear that there is a correlation between the amount of time spent playing official matches and the level of morale, coach \#1 shared this during the interview:

There were a few times where players wanted to play, but they were benched for whatever reason, and because I think that a lot of the players were new to team soccer, I felt that they didn't know how to handle being benched. Because when you're benched, you are still part of the team. The team is players that are playing and the players who are not playing. You're a team and everyone contributes for the team to do well. And I felt like a lot of people because they lacked soccer culture, they thought that they were not part of the team because the team was on the field and they weren't. And we would have players that would cry and 
not understand the process and maybe we should've dealt with those things like I said straight forward instead of trying to tiptoe around issues. Just like, "hey this is what happens. This is how soccer is." But then again, this program here is very peculiar. An Adventist institution, you're not playing soccer your whole life. You focus a lot on character development and even less on winning right, having the right tactics. You're just more worried about... are they doing well with God.

Although players experienced feelings of discouragement and low morale due to not getting enough playing time for the games, it is evident that there is a problem with communication between coaching staff and players which is further discussed in the Communication \& Structure section under Post-season Improvement. Per coach \#1's example, it is apparent that the coaching staff did not use effective communication in this particular aspect of the season to ensure that everyone understood why they were being benched in order to diminish the chances of those players experiencing feelings of exclusion and lower levels of morale.

\section{Conflict Management}

Consequently, when asked about conflict management, the team and coaching staff expressed a range of answers. 
Figure 5 Interview Responses About the Andrews University Lady Cardinals' Conflict Management

\title{
Andrews University Lady Cardinals: Conflict Management
}

\author{
Interview Responses
}

Conflicts never addressed/Conflicts avoided

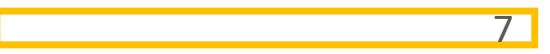

Conflicts are solved amongst players

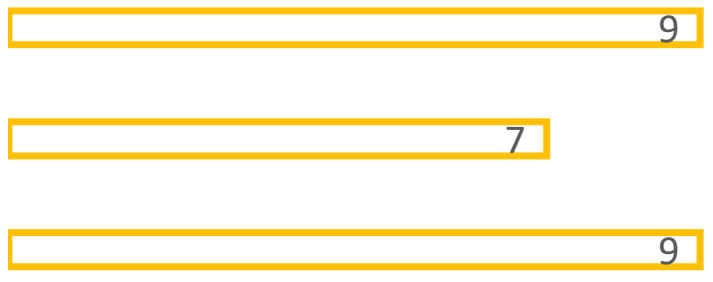

Conflicts arise due to Leadership

Conflicts are discussed on Facebook Messenger

0

2

4

6

8

10

Evidently, the Andrews University Lady Cardinals did not follow handle conflict resolution the way that studies suggest which was conducting team building early in the season, addressing conflict early, having mediators, and holding structured interviews could help to manage conflict" (Posada, 2017, p. 5). Instead, findings show that respondents' answers were able to fit four main categories (see Figure 5). The main observation is that the team did not usually address conflict, especially conflict between the coaching staff and the team. Firstly, in correlation to what coach \#1 stated about tip-toeing around issues, the following players agreed:

Player \# 12 stated, "Sometimes I feel like [disagreements] aren't really handled.... sometimes it's almost like nothing happened. And things aren't really addressed." 
Player \#9 said, "I don't think [disagreements are handled]. I feel like it's kind of like something that we skip around right. From what I've seen when it comes to like [one of the coaches, they] just kind of push it to the side and don't deal with it unless [they] feel like it."

According to these examples, not only do some of the coaches not address team conflicts, some coaches tend to avoid approaching certain conflicting situations. Moreover, there were nine instances where players expressed that disagreements and/or miscommunication occurred due to ineffective leadership abilities. Hence, the following examples:

\section{Player \#14 stated:}

I don't think [the coaches] really resolved an issue. I know [some of them] did. I know [coach \#2] resolved an issue once. And then [coach \#1] helps us out with [coach \#3] sometimes because sometimes [coach \#3] will go to do a drill and [they] word it weird like we won't understand, so then we start disputing with [them] because it's confusing, and then [coach \#1] will come in and clarify.

Player \#4 expressed her experience stating:

I think with the [coach \#3], though, we would all whisper and talk to each other, but we would never really confront [them] unless it was where [they] forgot something, or [they weren't] doing something. We would be like, "hey [ $\operatorname{coach} \# 3]$, can we do this, or can we have a scrimmage?" and [they] would just ignore us, or [they] would do something super rude to a player. And the girls would just whisper about it like, "oh my goodness I just asked [coach \#3] this and [they] replied to me like this." And then we would all be like, "oh my goodness, I can't believe [they] did that to you." And we would all like whisper 
and talk about it, but no one would confront [them] and be like, "hey [coach \#3], that's a really stupid thing you did" because [they] wouldn't take that well.

Coach \#4 declared their observations as well by saying, "I personally felt that there was some difficulty in communicating plays and plans to the team. It seemed to make sense in [coach \#3's] head, but [they] struggled to get [their] point across, leading to some disagreements."

The coaching staff came together at different points in the season as well. Therefore, it is evident that there were communication issues at times especially in the beginning. According to coach \#1, there were times where the coaching staff itself did not agree. They stated:

I think we definitely could've been more professional in how we handled the disagreements. There was a game that we were losing by a few goals, and part of the staff felt that we had to drop back, and I felt that we had to push up because if we dropped back, and I just thought it was such basic soccer like if you drop back you give the other team space to pressure, so we should at least get a few people to push up. And you know, the staff didn't really agree, but then the final decision [was made according to one of the coaches] and I agree with that organization structure. That's the way soccer works, and the decision was final.

Even so, the coaching staff was also comprised of four different people who also came together for the first time this season. Therefore, it was a process they had to endure to learn how to work together to effectively lead the team. Coach \#1 concluded, "With me and [ coach \#3] like the moment we clicked as far as just mentally and working together with [coach \#2] and [coach \#4]. Everybody had the same thing in mind, we committed because we liked working with each other and to see the development of the players and ourselves because we're learning new things." 
Although it is natural to have tension at certain points in any relationship, not every form of communication is effective when handling disagreements. The team concluded that most arguments were handled electronically on Facebook Messenger. According to Iishi (2010), "Compared to face-to-face interaction, social desirability may be reduced online, and people may not necessarily show a relatively high degree of concern for their online partner directly when they experience conflict" (p. 368). Evidently, the team had little to no regard for conflicts electronically. The team had a group chat entitled Lady Cardinals 2018. Coach \#2 confirmed the usage of the group chat to address disagreements by stating, "Disagreements were handled publicly on the group chat that the team had with the [coaches]." Certain limitations and issues arose in using the group chat as the main source of conflict resolution. The captains who were a connection between the coaching staff and players also did not agree with using Facebook Messenger to resolve disagreements. Player \#5 stated: "Most of the disagreements happened on messenger. I feel like most of the time, we end up creating a bunch of polls because no one can decide of what's like going on. Personally, I don't think that is the best way because like in the end, the [coaching staff] should have had like the final call on everything. I don't think disagreements have been handled well. Most of the time." Her fellow captain player \#2 agreed saying, "I feel like when we had disagreements with the coaches, I feel like us girls would talk about it in the group chat and we would like bring it up in the group chat with [coaches] and like try to talk to [them] about it, but a lot of the time a lot of people wouldn't respond or anything." The inconsistency of people responding to players trying to address certain issues is due to the fact that the communication interaction is not taking place face-to-face where the person is required to respond immediately. Even if the person chooses not to respond, they are responding 
because in communication, silence is a response. When people did respond, it could get hectic. Player \#10 expressed her annoyance regarding the Facebook Messenger conflicts by stating: There's a lot of confrontation in the messages, and it was so annoying because I was just trying to study, and it was like ping, ping, ping. But I don't think [one of the coaches] had any authority from the beginning because [they] just had no backbone. [One of the coaches] like definitely didn't even try to like gain their respect through the season which I think also threw off the group dynamics.

One player shared one particular interaction with one of the coaches in regards to the group chat that she found disturbing. Player \#8 stated:

[One of the coaches] said that we weren't allowed to have a group message without [him/her] in it... I've played sports all my life and the coaches just know that the girls have their own group chat and the coach would just tell the captain like, "hey, please tell the girls this.” But [this coach] was like, "if I find out that you guys have a group chat, without me, there will be serious consequences." And I was like, "what the heck?"

Nevertheless, regardless of the inefficiency of conflict management between the coaching staff and the team through Facebook Messenger, there were nine instances where the team itself described its conflict resolution. Player \#14 stated:

If we had a disagreement, we would usually come together and talk it out. We wouldn't just avoid the issue and wait until it was too late. The team would talk about it. We usually go to the person if we have a disagreement with them. In a game, me and [player \#5] were having a disagreement about something and at halftime, we were able to work that out. We kind of just resolved it with the team. 
Player \#9 agreed stating, "The girls on the team, I feel like they do work more on talking things out, so like if they have a problem they will bring it up and actually hash it out which I think is much better than the other way around."

When comparing this to what was observed during practices, it is evident that the players were able to establish genuine friendships. Because of this, the level of trust perceived by the women amongst each other was high. This is also apparent in the close-knit relationship dynamics the team presented this soccer season. Therefore, this high level of trust aided the players in their conflict management pertaining to each other. 100 percent of interview participants stated that they were able to talk to their teammates about everything not just about soccer. Coach \#1 summarizes this perception of their relationship clearly when they stated, "[The players have that] feeling that they belong, that they are valued, that they have friends. Like they made real friends. They established real relationships. It wasn't about the score. It was about playing with your friend. Putting out the effort for your friend.”

\section{Preseason: Tuckman's Stages of Group Formation}

During the 14-week study, I was able to observe the different stages of group development through Tuckman's model. It was interesting to visualize the different stages throughout the season. In studying the various stages and their elements, I was able to use Tuckman's theory as a guide/framework for this study in order to conclude the length of each of the stages the team experienced. It was interesting to use Tuckman's stages of group development as a guide to recognize the interpersonal progression of the Lady Cardinals at the beginning, middle, and ending of their 2018 soccer season. 
Figure 6 Tuckman's Stages of Group Formation and the Lady Cardinals' 2018 Soccer Season

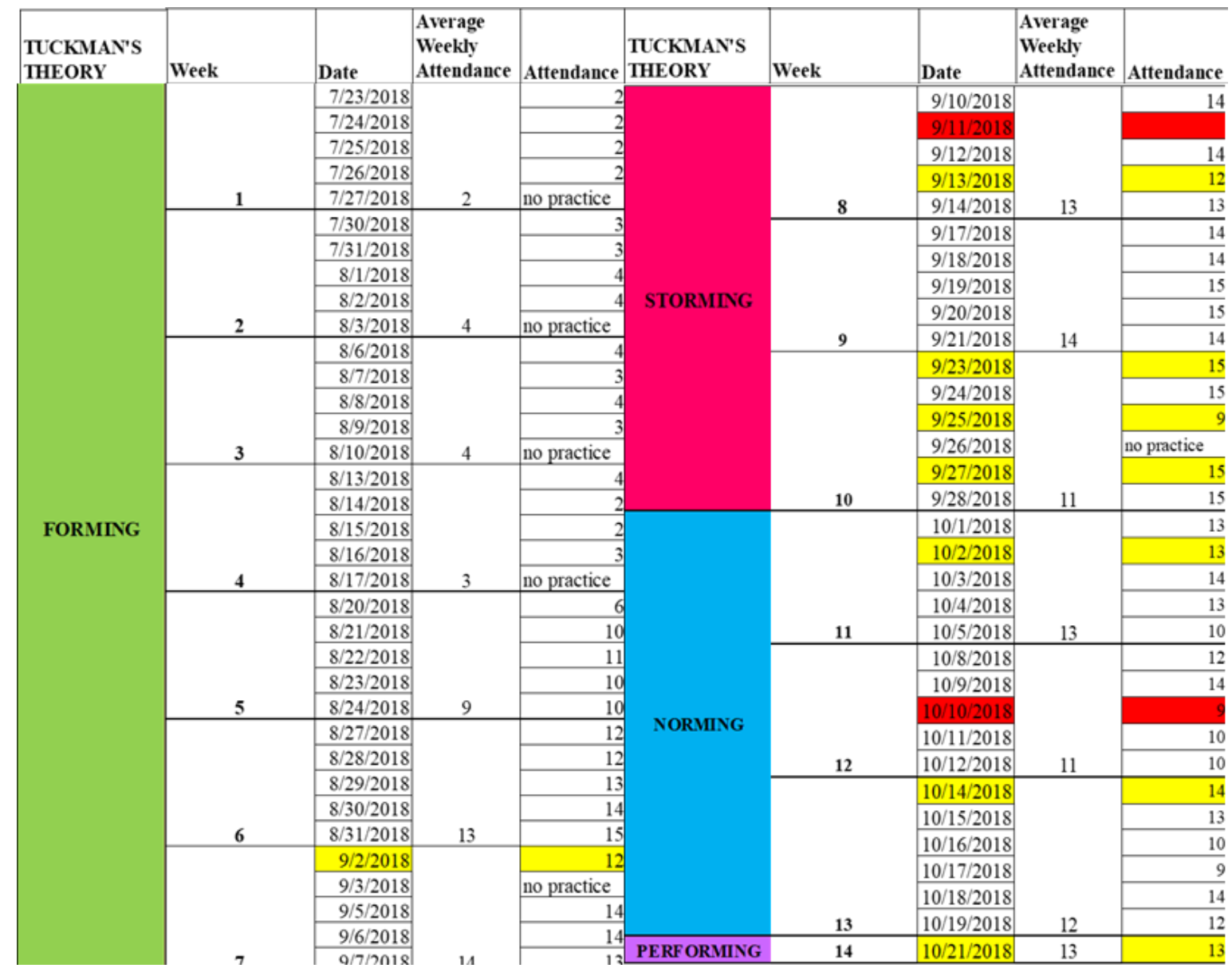

A simplified version of the daily observation chart used during the season to keep the data collected organized (see Figure 6). I observed as the Andrews University Lady Cardinals developed relationally, then mapped as the entered the different stages of group development in Tuckman's theory.

Firstly, the season began on July 23, 2018. That was the start of the preseason. The problem with the preseason is that attendance was very low mainly because most if not all of the players leave for summer break only to return close to the first day of school on August 27, 2018. This explains why the phrase, "I wasn't here for preseason" was mentioned in some variety 10 times by the players when asked for their thoughts about the 2018 season. The first game of the 
season was on September 2, 2018, but the team was still in the forming stage of Tuckman's group stages. Another problem arose when players would come and go day by day. Therefore, the team had difficulty getting to know each other and meshing together. The players were constantly changing because some would leave the team and others would join. It became difficult to track the data, so a criterion was made for players to be included in the study. Clearly, there is an issue when the first game has passed, and the team is still in the forming stage. It should come as no surprise that the team did not do very well that first game. The score was 11-0 which was their worst loss of the season. Preseason was not very effective practically since attendance was so low and also, there were no drills besides running. There was no variety. Player \#6 stated:

That was not a preseason. That was a sad preseason. I have seen preseasons. I mean we ran which is good obviously to keep in shape, but like what I'm thinking preseason, at least in high school we had like a whole regiment and people would be there who signed up... I know some people were out of state because they hadn't come to the school yet, but I know maybe it should have been a different time or something, so people didn't feel like they had to catch up when they came to the team. It wasn't a good system. And even with the preseason because all [the coaches] would say is run and other than that really we didn't do anything else.

It is evident that the preseason was inadequate. Coach \#1 confirmed stating:

There was no preseason. There was a "preseason" like a few people running, but I mean. There was no preseason with me, I heard about it. A few of the girls were running about 5 or 6 of them, but they were just running. Yeah... I've seen preseasons and that was not a preseason. That's a few people getting together which is good, and I have done that 
before, but as far as team preseason, it didn't exist as far as I see it because I know I was brought in a little bit later, but no.

Unfortunately, the players understood that because the preseason was not structured or planned well, they struggled to reach the second stage of Tuckman's theory which is storming.

Figure 7 Andrews University Lady Cardinals' Attendance Progression During the 2018 Soccer Season

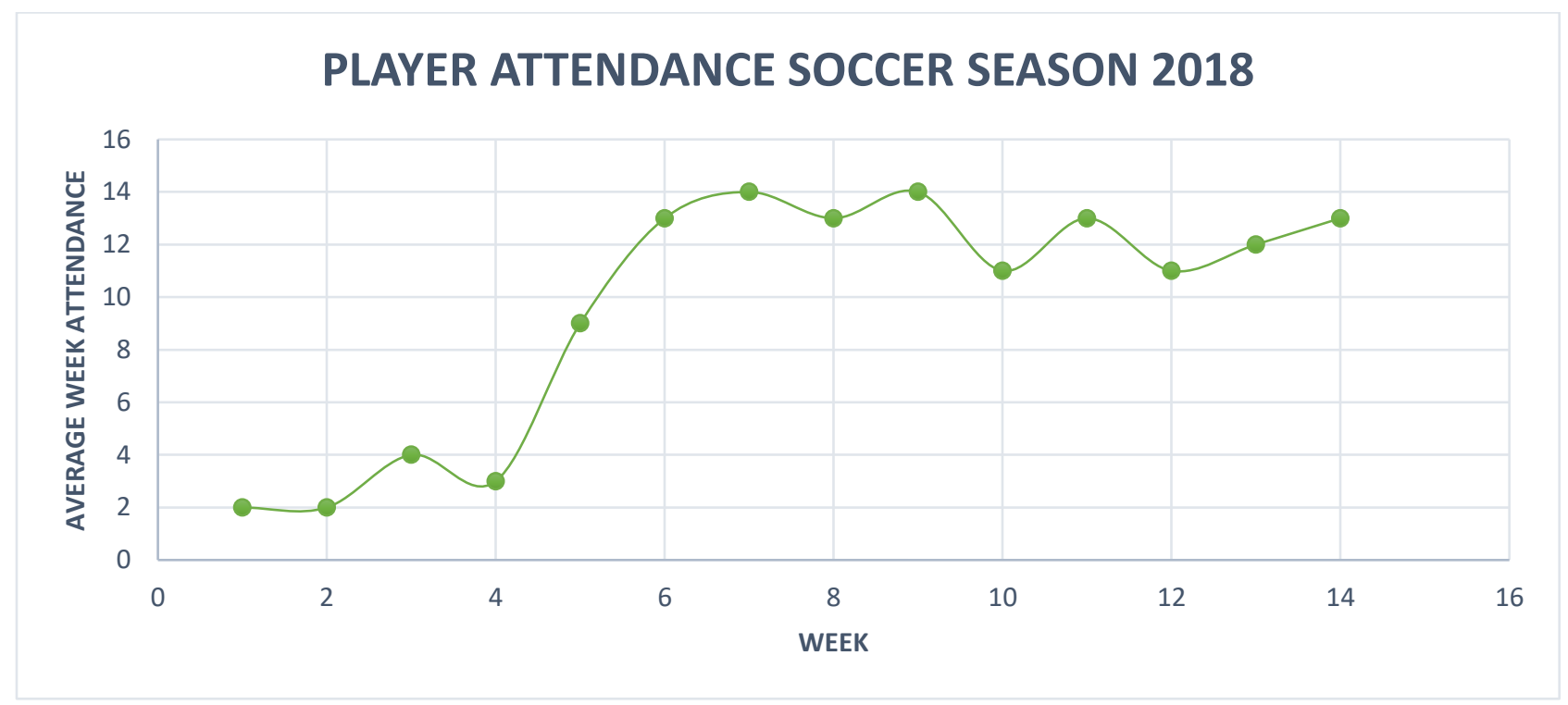

It is evident that weeks one through four were extremely low in attendance in comparison to the rest of the weeks starting in week six which was the first week of school (see Figure 7). Most players would have preferred an intensive preseason that included a variety of drills and exercises. Having a preseason is important because it also aids in the relational dynamics of the team in that they get to know each other better. Studies have shown that players who are closer outside of soccer play better together on the field. On a professional level, Lionel Messi, Luis Suárez, and Neymar da Silva Santos Júnior have been Barcelona's most dangerous attacking trio in Barcelona's history. According to Fox News, "In 2015, Messi (42), Neymar (39) and Suarez (39) scored more goals for Barcelona (120 total) than the entire Real Madrid team (106)" 
(Hautmann, 2016). This also occurred on the Lady Cardinal's soccer team. Player \#16 observed, "I think one thing that I saw when [player \#13] and [player \#12] played, they communicated. [Player \#13] told [player \#12] to run, and she kicked the ball for her to receive it. That's how we should play. I really admired how they played together. [Player \#11, player \#12, and player \#13], they communicated well.” The interesting thing about this is that these three players, (Player \#11, player \#12, and player\#13) are the closest group of players on the team. They are best friends. From talking to them and observing them, it is clear that they are close-knit. I often see them hanging out outside of soccer. In fact, the day I interviewed them, I did it back to back because they were all studying together. When asked, "What other 'groups' [of players] can you see present on the team," every single player stated their names as one group.

Moreover, reaching the second stage of Tuckman's theory, the storming stage took a while. It was clear to see the players gain more and more understanding of the team and how it worked after the first game was played. Going into it, it is evident that players were not too sure as to how things were going to work, but after that first game, that is when players started understanding the purpose of the team more and more. There was not too much conflict observed, but it was apparent that people were getting to know and understand each other.

Thirdly, during the norming stage, the players were figuring out their roles and responsibilities. During this time, the captains were chosen by the coaching staff. Although there were disagreements as to who should have been captain amongst the team, players accepted their own positions and accepted the captains chosen. Observations made during this stage show that players were growing both in skill and interpersonally. Also, it was nice to see how the players started to enjoy going to practices. The players stated that it was not because of the coaching 
staff or the warm-ups, but because of other team members and the relationships that they were cultivating.

Lastly, it is sad to say that the Andrews University Lady Cardinals soccer team barely touches the performing stage of Tuckman's theory. Unfortunately, information collected from interviews and from observations concludes that the season ends when the team is reaching its peak performance. When asked if the team reached its full potential, one of the captains expressed:

It goes back to the fact that there was no preseason. And um... immediately we had a game within like the next week. We didn't even really know each other. There was like no bonding or chemistry I guess you can say. And so that just definitely set us back immediately. Just the fact that we had just reached the top of our game at the last game because we had such a short season so just the lack of time, the lack of games just really like cut it short for us because it's like we were just getting started to know each other and how to play soccer. And that should've been maybe middle or beginning of the season Player \#14 stated:

There's like no preseason. I think we definitely need a better preseason. I think by the end of the season we were where we should've been the beginning or at least mid-season. If we had a proper preseason, I think one thing for me is that I'm not very strong and at my old school we used to do weight lifting and our conditioning running stuff. We would do drills, but it was more focused on team building. Passing around making plays things like that. We would get our conditioning in the morning and then we would have a whole 2 hours in the afternoon. So, we focused on getting better as a team. I felt a lot stronger and more stable. Also, these girls are really aggressive. I feel like if we would get that extra work in to have that strong core and legs it would help a lot. Also, like hanging out with the team 
outside of soccer. I really enjoyed having little get together outside of soccer on my old teams, so I think that during preseason we should do a trip after all the hard conditioning we would be doing. We should like grow as a family. I love talking to them and stuff, but I feel like if we hung out outside of soccer, we would know each other a lot more. Just to do a fun trip like that to reward us for the hard work we'll be putting into this season. To get us hyped and I feel like it would be a very great opportunity to grow as a team. On a spiritual aspect of things, the worships we had were good to start practices off with, but maybe trying to go to church or vespers as a team would be a really good spiritual thing to do as a team and to grow. Because we are going to Andrews and paying to be here and it's an Adventist school. For me, I want to grow in God that's why I'm here. I could go play soccer in any school, but that's why I came here because I want to grow in God. Those worships were great, prayer is great. I totally believe in prayer. It works, but just doing more spiritual stuff on the team would be kind of cool. The time is worth it. Plus, preseason should be before school. I know that other schools start at least 3 or 4 weeks before school and that's really good because then you're at your peak of fitness so when you start your season, you only have room to grow from there. As a team, I think that by the end of the season we were really starting to peak which is sad because it was like the end of the season, But I think that preseason will definitely help with reaching our full potential.

One of the stages is missing: the adjourning stage. After the last game of the season, there was no last get together to discuss the season. There was a soccer banquet in which players received awards and medals, but the season was not discussed for improvements or other concepts which should have been talked about. Instead, the banquet consisted of a nice meal, awards, and pictures. 
In summary, the team was unable to reach its full potential due to a number of factors, but the main issue was time. However, the team was successful in building the mental aspect of soccer and establishing genuine relationships. Coach \#1 described it in the following words:

[We did not reach our full potential.] Definitely not. That was definitely new to me because the potential here... I had to reassess the potential of this team versus a team who had players who have played soccer their whole lives because the potential there would be did they reach the numbers? The goals? The passes? The percentages that we were looking for. And if they didn't, they failed. I think that the team could've done so far better with just honestly basic soccer disciplines, passing, shooting. We could've done so much better if we had had a little bit more straightforward communication that, "Hey guys, this is what we need to work on better. And this is what we're going to do for the next few weeks." But again, because of the time frame, we had 2 months. It's impossible. Like impossible to do anything. I wouldn't say impossible, but very unlikely to develop players, especially with this program you have a lot of new players with 2 months like what can you do with 2 months? You know? So, I think as far as mental potential, of attitude, of just having commitment through working through a difficult situation of not winning. Getting to the end of the season. The last game we started losing and then we won the game. So, for that to happen after a tough season, it took a lot of effort from the players. They played their hearts off and it was so cool to watch. So, seeing that, to me the team reached its potential in the sense of one of the aspects that we wanted to create which was the mental aspect of I am part of a team. I need to work through whatever happens because we're working towards a common goal. And I needed to reassess my goal. At the beginning, we want to have a winning season. We want to win, but then you start playing with a team and you 
have to reassess and say if you have unrealistic expectations, then you are going to fail. You need to set realistic expectations, so within the realistic expectations that we had I think we did extremely well with the mental aspect, but we failed with more of the professional, raw side of soccer of, "Hey guys, we're going to run until you can't run anymore. You might want to puke, but that's normal." I felt like we couldn't do that because the mental side wasn't developed enough at that point because if we had done that, I think a lot of players wouldn't have come back. They would think soccer is horrible, I don't want nothing to do with this. It took us 2 months to just say, "Hey soccer is fun. Come out again even when it's not fun.” And right when we were getting to the point where like [player \#2] ... she took a shot from like midway from the soccer field at like practice and I yelled from the side, "Take the shot!" And she just like looked almost like no, but she did it and she scored, and she surprised herself. And that to me was amazing because she surprised herself that her abilities had progressed a lot more than she even herself thought. And I felt that the whole team was like that, but it took almost a whole season for us to show the team that you guys can compete, that soccer can be fun. It's okay to want to win, and it's not going to be fun all the time, but it's an amazing sport. Like, buy into the sport in a general sense. But right when we bought into it, the season was over. And people were excited to come to practice. It was really getting fun and then the season was over. So, we developed a lot of the mental aspects of soccer, but we did not get to the physical. We really didn't. Like it was just like come out, we'll practice, we'll try to do something, but yeah. We didn't really get to that. 


\section{Post-season Improvement}

\section{Ineffective Communication in Leadership}

Solely based on the interview responses, there were 85 various examples of perceived ineffective communication in leadership from the team. One of the coaches was the subject for most negative accounts, however, three out of the four coaches were mentioned in a negative light by various players. Not everything about the leadership was bad, however. In fact, some players stated that they appreciated the coaching staff's effort. Even so, it is evident that one of the coaches, according to the players and coaching staff, was not qualified to hold a position of leadership on the team.

One example of ineffective communication occurred repeatedly at practices. I observed as this coach struggled to explain what they wanted the players to do for the drills of the day. Focusing specifically on practices, the following are team descriptions of this coach's communication:

Player \#15:

Personally, I pretty much avoid talking to [them] about anything at this point because it's gotten to the point where [they're] basically unapproachable, so if I have questions, or if I'm confused about anything at practice like I'll ask [them] what's going on if [they're] like running a drill and I have no idea what's going on, but [they] just won't answer me. At that point, I just rely on the girls to help me. With the team, we can talk about everything.

Player \#7: "Practice is kind of confusing because sometimes [coach \#3] will say something and no one understands what [they say], so we will kind of interpret it ourselves and everyone will kind of just follow however everybody else is doing it."

Player \#10: 
[Coach \#3] really tried to like encourage the girls to like play hard and stuff like that. But I really like I didn't think it was genuine. So that's why like... the lack of genuineness was kind of... we could kind of feel it. So, I don't think [they were] a good guide for us. [They don't] give like very specific Instructions, like I think it's very helpful when someone is like, “Okay, like what you just did right here... that's wrong. Like, don't do that. So, let's do this instead." And then repeat it several times. [The coaching staff] is supposed to do that, but [Coach \#3] didn't do that. [Coach \#3] would just like give us a vague description of what [they] wanted. [They'd] be like, "Oh, okay girls," and like that was all [they] would say. So, I was like, "No dude, like give us the play and then we will do it." The only times [they] actually did do that was when we were like practicing like the triangle. Like basic soccer. That was the only time.

This coach ineffectively communicated at practices. In fact, according to player \#14, "Practice communication, I think [coach \#3] means well, but [they don't] explain it right. It's borderline understandable." Yet, the relaxed structure of the practices allowed other coaches to step in and explain more clearly the different drills and minimize the confusion of the players. Other coaches would have to step in because according to player \#7:

[Coach \#3] just kind of says what we're going to do. And we just like do it... usually. Yeah. Um, I think [Coach \#3] has really poor communication. I don't know if it's like a language barrier. Maybe [they communicate] better in [a different language]. Often, I found that when [they] tried to explain a drill like everybody was just confused and usually it took like at least two or three tries for us to get it right because we couldn't understand what [they were] saying. And I often thought that there was a more efficient 
way to do it or like a way where we would learn better, but it was never voiced because I don't think anybody wanted to like step on [their] toes.

The problem became greater during official matches because mostly the whole coaching staff would be involved in directing and helping the players on the field when all four of them attended the games. Therefore, the coaching staff would be shouting out various commands which would sometimes lead to confusion amongst players on the field during the games. Coach \#3, in particular, would communicate ineffectively, yet in the heat of the game, the other coaching staff usually did not take the time to intervene and clarify. The following are examples of different, yet similar experiences the players had with coach \#3 during games:

\section{Player \#13:}

[Coach \#3] always always confused me when [they were] on the sidelines during the game. And also, [they] would always say to do stuff on the field that I disagreed with such as um... making me stand back. And at least in the last game when I would not stand back, when I went forward when I went more in offense, I played better. You know, but at the same time defending my zone. So, I just felt like [they] made me very limited because we were in such a defense mindset you know. And I didn't like feeling limited. I felt like that ruined the game for me. Like you want to do something, and you can't do it because there's someone that is holding you back and not believing in you that you can do it. There was a period of time where [they] wouldn't put me in, and I feel sure that it was because of the tension that there was between us. [Another coach I had in the past] didn't make me feel at like that at all. He would always always believe in me like he thought I could do it. He thought I was a good player even though it was literally my first time playing so yeah.

Player \#8: 
Like [coach \#3] kept throwing me from being a goalie to being a mid to being a defense, like throwing me everywhere. And I was like that's fine, like, "You can throw me from defense to being a mid, but like throwing me from goalie to actually playing on the field is like really different. It's like what I am practicing like I have to choose. You have to put me on something so that I can learn or else I won't learn.” [They were] like, "Okay, okay, okay.” And honestly, [they] never communicated with me. [They] honestly made me feel like [they] didn't want me to play, but I was always there.

Fortunately, there were a few times where other coaches would be able to help out. One example of this is one of player \#14's experiences. She describes the situation as:

There were some things on the field that were communication issues. I guess in the last game [Coach \#3] had switched me and [player \#5]. I was trying to ask [them] like are we switching back for the second half, but [they] couldn't tell me. [They] just like... didn't tell me. [They] just started talking to somebody else! I was like okay. Then [player \#5] asked [them] and [they weren't] even listening to her. So, we were kind of not knowing what to do, but then Coach \#1 worked everything out.

Practices and games are important in the development of players. Therefore, it is necessary for the coaching staff to effectively communicate directions in order to guide the team successfully as good leaders should do. 


\section{Player Retention and Commitment}

Figure 8 Positive and Negative Factors that Affect Player Commitment and Retention According to the Andrews University Women's Soccer Team's Interview Responses

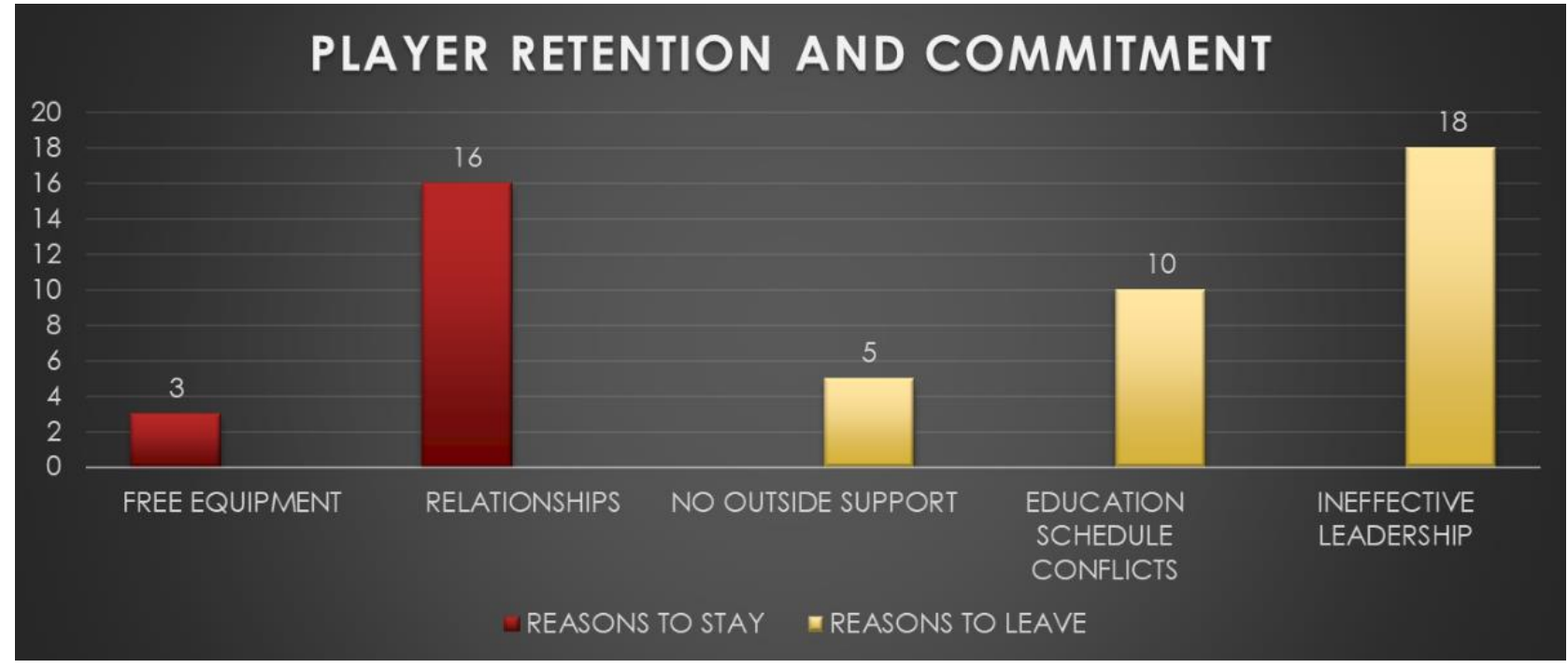

When studying the retention and commitment of players, interviewees answered a variety of reasons why players would choose to leave and also reasons why players would choose to stay (see Figure 8). Interestingly, staying for the "free stuff" was not a prevalent reason for players to stay on the team. In fact, every player expressed establishing relationships on the team with other members as the most important. Specifically, establishing true friendships which has been a recurrent theme throughout the study. In regard to this, coach \#1 stated:

I think it goes back to the players that felt that that team was a family for them, they didn't care what the score was, how far the game was, they were going to come out. And they were committed for the whole season. Those who felt included and honestly, the girls that felt that they bonded with each other and with the staff, they were committed for whatever was to come. The players that didn't click like on a personal level. Just honestly just being friends with one another. The ones that didn't had less commitment than those that did. The ones that did, they would go through anything with each other. 
It was apparent that players who had friends on the team were excited to come to practices and games throughout the season. It makes sense because those players who were able to connect found their place in a group of people. They had a sense of belonging. Other players who are not specifically included in the study due to not meeting the criteria left the team quickly. These players were late players who did not experience the bonding that most of the team experienced throughout the entirety of the season. Player \#13 stated:

The other girls [that left], they both weren't able to connect with the other girls on the team. They weren't able to find their niche. I feel like when you feel like you don't belong, you don't want to stay in that place. And I feel that's what happened. They came late. The first time they came it was photo day, so everyone thought that was really late and weird. And just because when you come late during the season, we already have our own little chemistry and our own thing going, but I mean that didn't stop us from being nice to them. I feel like I was welcoming like even on photo day, I still said, "Hi," and interacted with them. I just felt like them coming late was a great factor for them leaving so fast.

Nevertheless, the number one reason for players to leave and not be committed to the team is ineffective leadership. The players reported that some of the coaches were not approachable. This is troubling because there was not very much open communication between the coaching staff and players. Coach \#1 confirmed this by stating:

We lacked being more straightforward in communicating the negatives with the players fearing that they would be maybe hurt with whatever we were going to say. Because we had a lot of new players that had never played soccer, so you have to walk a very fine line developing them as a player, but also as a person where they're not going to want to just leave because their feelings are hurt. And they don't want to come back. So, there were 
several times where we could not express several growth areas that they needed to work on because honestly, we didn't know how to. And as a coaching staff, we really didn't spend time talking about those things. So, a lot of times, they were just overlooked. Throughout the season, what we focused on was more of if you come, that's already great, and that's enough. But that's not enough, if you come, you're here, put out the effort that you should. And we lacked being able to be more straightforward with each other as a team. You know if the team lost by 10, you put out a good effort, but we need to do better. We need to train harder. It's not okay. Let's just go home and have fun. It's not, but that's how it was. And as far as the inclusive aspect of that, because we didn't have a captain with a lot of experience, I felt that there was a loss of connection between the staff and the team because we couldn't translate some of the advice that we had into a language that the players would understand because obviously, we're older. Coaching staff to players is a little bit different dynamic and when you have a captain who understands advanced tactics, the captain is one of their own and they can communicate what's happening. And because our captain was very young, she did amazing, she put out the best effort, but there are things that just come with experience. You know, and it just takes time. So that's one thing, the bridge in communication between staff and the players, and we didn't know how to bridge it to talk about more straightforward topics.

This concept of being too nice with the players presented an issue to the team. On one hand, the players wanted to be pushed. They wanted structure. They wanted to understand how things worked; how to play real soccer. And on the other hand, the coaching staff was divided amongst four people who had different soccer experience, different personalities, and different ways of understanding coaching in light of leadership. The organization of the coaching staff affected the 
organization of the team. Coach \#1 described why the coaching staff had trouble being more direct about things, but on the other side, this is what the players had to say about how they viewed the coaching staff and what the team itself would have preferred:

Player \#6:

I don't really know how to explain it I mean. [Coach \#3's] leadership was kind of okay. Like [they] had [their] power, obviously [their] leadership. But [they] never set up rules or real boundaries, so it was more of like wishy-washy.. not like [previous coaches] who knew what was happening. Like [ coach \#3] was like, “Oh, I didn't know this was happening." And I'm just like, "Can you give me a plan and let me follow it." That's what I would have liked. [They're] not really direct. I would say more indirect.

Player \#4:

I think in [coach \#3's] brain, [they have] what [they have] to say, and [they think they are] very clear when [they say] it, but [they're] not. [They go] all over the place. [They start] off on one end and [they end] up at another end and there's no correlation between the two. And it's just very unclear like what [they say]. To be honest, if there was a communication problem, [they were] not very upfront about it. [They were] very passive-aggressive, or [they] would never call out people like specifically their names usually, [they] did a couple of times, but not usually. But [they] would be like, "Well if you did this," and you knew who [they were] talking about. Even though [they] would talk around the issue, you knew [they] were talking about you, but [they] would never text you personally to fix anything. [They] don't have the audacity to do that. If [they have] a problem with you, [they're] going to go around in circles. 
Unfortunately, being "too nice" as a leader can be detrimental in the growth of your team. In fact, one of the late players, player \#16 stated,

One thing that I saw as a new member, I told [one of the coaches] that I had no idea about soccer rules. But [they] didn't tell me the rules. When we went away to play, I was lost when they did the corner kick. I didn't know that I had to go and stand by the post, you know cover the post. When the goalie kicked, we had to be out of the box. I didn't know that. [They] didn't tell me. [They] didn't tell me the basics. I think it's good to communicate and tell the rules to all the new girls who just come late. The girls needed [coaches] that would communicate better. Someone that they could respect. [Most of them were] too friendly.

In turn, players on the team felt that some coaches were very stuck in their ways. Players felt that some coaches were inapproachable because of the way they would not tolerate suggestions or in the player's opinion, "Abuse their power." The following are different player experiences regarding leadership and feedback this season:

Player \#9 stated, "It's like kind of a one-way thing where [some coaches] tell us what [they want] but [they] won't take any feedback either from us. So, I feel like it's not super effective because that kind of just frustrates us because it's all kind of [them] telling us what to do but not us having any input whatsoever.

Player \#13 stated:

I feel like I'm not comfortable telling the [coach \#3] anything that's serious about the team.. just because I don't feel like [they take] my word seriously or [they] never [understand] what I'm saying. Like I never felt like [they] understood any of the girls. [They] would always be very close-minded. Honestly, I couldn't confide in [them] for anything. [They 
tell] us stuff, but they don't guide us to success, they guide us to confusion. Like everything [they] would say to us, every word was just confusing. Everyone was just confused, and we would have to find a solution on our own. It felt very independent this season. Just because we didn't have someone there to lead us. [Their] communication style was very authoritative and very ignorant. Like [they] demanded it. [They] thought [they were] right no matter what. I actually feel like... having [that coach] be the way that [they were] with us made us all have something in common: that we all disliked [them] and that we all could not interact with [them]. I feel that that actually benefited us, like the girls, in that it united us because we had that common anger and frustration towards [some of the coaching staff]. Some of the coaches also had opinions about different coaches on the coaching staff itself. Coach \#2 also stated that some coaches were unapproachable. They stated, "[Coach \#3] had more of an authoritative style of communication. There was not much conversation much more commands." Coach \#4 agreed stating:

From my perspective, [Coach \#3] took an authoritative stance/approach. [This coach] would often have a plan in mind and not stray from [their] plan, even if changes needed to be made. Also, sometimes it seemed like [they] felt the need to control everything, including teammate communication. I personally felt that there was some difficulty in communicating plays and plans for the team.

Player \#14 decided to share a specific account which was also described by player \#12 where one of the coaches was not able to effectively handle a situation that happened after the last game of the season in which supporters accompanied the team on its trip to Ohio. The two players had this to say about the situation:

Player \#14: 
So, [this coach] needs to communicate like if [they're] having issues with something. Sometimes [they] would tell us, but it wasn't portrayed properly. [They were] unprofessional with some of the stuff. Like with the whole dilemma with the bus ride back... What happened is that [player \#2 and player \#6] went to the car instead of the bus where we all were, and [this coach] would not move until they came back. Literally, there's people that would go in the bus to replace them, but [this coach was] like, "We're not leaving until they get back in this bus, and I don't care if we have to sit here all night." And it was just kind of childish. We're still going to get there the same way. So, I thought that was not professional. [They] could have talked and worked it out with them, but instead [They were] just childish and [were] like, "Well I'm not going to move if they don't come back here and stuff like that." [This specific coach] uses [their] power in the wrong way. [They] like [abuse] it.

Referring to the same problematic situation, player \#12 stated the following in detail:

Yeah...um,... [Certain coaches] didn't seem like [coaches]. Like the day that [One of them] wanted to leave [player \#1's] boyfriend and my brother... So, we were on the bus because we had just played the last game where some of the boys and [other people] had come to support us. And [the supporters] were all in [player \#2's] car because she had let [the supporters] borrow it. Um... [player \#15], you guys, and [three of the Cardinal men one of which was] my brother were in the car... So, when we were done with the game, we stopped at Five Guys, and... [player \#2] and [player \#6] got off the bus and told my brother and [player \#1's] boyfriend to come on the bus. And so, my brother asked the [coach that was driving], "Can I sit up here in front?" and [that coach] told him, "No, you can't come here." And we all thought that [they were] kidding, so we all started laughing, but then [they were] like, "No, really you can't come in here." And we were all just like, "Why?" And [they were] like, "No... he can't. He can't come in here." And so, then [player \#6] came to give 
[my brother] his bag because he had left it in [player \#2's] trunk, and she said that there was no more room in [player \#2's] car for my brother. And after that, [player \#1] and her boyfriend came and [that specific coach] started to tell us, "You guys go and tell them in the car that [player \#6] and [player \#2] need to get off that car. They have to be in here." And so, [player \#11] and I were like, " You are [one of the coaches], why don't you go and tell them... they aren't going to listen to us." And [they responded], "No." So, we were like, "What?" .... So, after that, we started to tell [them] like..."Well if [my brother and player $\# 1$ 's] boyfriend don't come with us because there is no room in the other car, and they can't come in here, then we are going to stay here too." And this was [player \#1], me, and [player \#11]. So, we all started to get out of the bus. And [that coach] just kept saying, " You guys go and tell them because I am not going to say anything." [They] said something like, “That's illegal" or something like that. I don't know. To be honest I didn't even understand what [they were] saying. So, like a lot of time passed, and then I think that's when [that coach] got mad and my brother didn't even want to get in the bus at that point. He started to tell me like, "Why did I come?" and things like that. So, I started to push him, so he could get on the bus and he didn't want to, so [the coach that was driving] finally got down, and all we saw is that [they] came back with [player \#2] and [player \#6]. So, [player \#1's] boyfriend and my brother left. After that, everyone was just upset and complaining. That's when they said that if [this specific coach was part of the coaching staff] next year, then they didn't want to be on the team. So that's like [their] communication like [they're] not even [part of the coaching staff]. Like that's [a leader's] responsibility and [they] just sent us to do it like if the other girls were going to listen to us. 
In summary, a situation that could have been avoided from the beginning expanded to be a greater problem than necessary. Any leader establishes rules and boundaries. Perhaps if the players would have known that it was unacceptable to ride back to campus a different way than the way they drove to the away game, then maybe the players would not have attempted to change vehicles on the way back because they would understand that from the beginning, that would have been established as unacceptable. The players involved felt that the leader in this situation acted in an irrational matter as the leader chose not to use communication to solve the problem. Instead, this coach decided that it would be best to let the situation unfold by prolonging the time spent demanding the players themselves solve it. It is unfortunate that this is just one specific circumstance among many.

Both No Outside Support and Education Schedule Conflicts (see Figure 8) can be combined to also fall under Ineffective Leadership because they are problems that arose during the season because the leadership was incompetent. For example, during the bus situation, player \#12's brother was one of the three Cardinal Men who had decided to take the four-hour trip to Ohio in order to support the Lady Cardinals at their away game. When the problem unfolded, player \#12's brother had started wondering why he had come. It is unfortunate that he felt this way because according to the players, supporters, particularly the Cardinal men, played an important role in the team's success. In fact, this occurred after the last game of the season which was a win against Mount Mary Angels. The Lady Cardinals had won 2-1. One of the captains stated this about the leadership during the situation:

[One of the coaches] has some stuff that [they're] kind of... like you have to be careful with [them] .... like some of the other girls like they didn't want to talk directly to [this coach], and they would like ask me if I could talk to [them] because like at least part of 
the season I was like one of the captains. Like we had a dispute about leaving for one of the games and like I tried to talk to [them] about it, but I don't know. Sometimes [they shut] down and [they] kind of [want] to have the final say on things. I don't know. And I tried to talk to [them] a couple of times about switching up some of the positions, but [they] wanted to keep it like [their] way or whatever... I think [their] communication could be better. I feel like [they] could have better leadership skills. [They are] kind of too passive sometimes... and sometimes [they] will like get upset with us and it will just put everyone in a bad mood. You can just kind of tell by [their] facial expression. [They] will like cross [their] arms and be shaking [their] head a lot. [They] won't voice what [they have] to say. [They] just kind of like [look] annoyed.

As for the scheduling conflicts, because there was so much disorganization, the players expressed how difficult it was to schedule their time around practices and games. Everyone agreed that communication could have been better. They shared the following:

Player \#1 stated, "Communication [...] is not very effective. On multiple occasions, we've asked questions about the games like what time is the game, when are we leaving, things like that, and we won't get the answer until the morning of, or like while it's happening which is quite frustrating because it's hard to plan your days."

Player \#14 shared:

[They] didn't lead us very well... [coach \#3] doesn't lead us super well. [Their] communication style is not communicating. Procrastinating communication. [They] would tell us everything last minute. We would have to ask like when we were leaving which [they] should just tell us when we're going to leave days before we're leaving. So that was a communication issue. Like when it comes to making decisions like if we're going to have 
a game, we should have a good idea about what time we are going to leave, what vehicle we're taking, like who is going to get what, but it is literally decided] the night before. If someone doesn't say anything, [leadership] won't even say anything pretty much.

According to player \#13, "Like for example, if somebody needed shin guards, or like if we needed to discuss the time and stuff like when to get there, it was the girls who initiated that conversation of what time we needed to get there you know? Instead of the [coaching staff] initiating that, it was the girls who always initiated like the times that we needed to arrive at the bus and stuff like that.

Finally, from a captain's point of view, player \#5 stated:

[Coach \#3] ended up forming like the group chat which I mean I guess that was good in a sense because I guess it was something we could all check more and we could all see what was going on. But there were sometimes when there was like a lot of lack of communication as to like if we had away games, like what time we were leaving, and all that, so yeah. Simply, having everything planned ahead [would help improve the team for next year]. Everything seemed pretty rushed and like last minute. Personally, I took it upon myself a decent amount of times to just like figure things out because the [coaching staff] wasn't, so just like trying ahead.

Not every coach on the coaching staff was mentioned in the examples of ineffective leadership. However, for the future, one thing that the team said would improve the team's performance and group dynamics is the improvement of leadership, especially regarding communication. Coach \#4 summarized it nicely when they stated, "Finding [coaches that are] not only knowledgeable but also someone who is respected by the players. The communication needs to be improved between the coaches and players." 


\section{CHAPTER 5}

\section{CONCLUSIONS AND RECOMMENDATIONS}

\section{Conclusions}

RH1: Team members with higher skill levels will be valued more highly by the coach and other team members.

According to data collected through interviews and observations, the coaching staff valued the captains, specifically player \#5 because she took initiative in helping out administratively. She would help with paperwork and it was also observed that she would often participate in decisions as well. However, due to the fact that the team was a close-knit group of players, no one had ill feelings towards player \#5. The only thing that would sometimes bother people, according to interview answers, is something that player \#5 also admitted to which was her inexperience being on a team. Other team members felt that it was interesting to have a captain who had never played soccer or been on a soccer team.

On the other hand, the team itself valued each and every one of its members. It is evident that there was an immense amount of positive communication among the players. Even though, in the beginning, there was negative communication among the players during official matches, everyone who was interviewed understood that it was due to the heat of the moment and the intensity of playing in the game. The players felt a sense of belonging which was found out to be the main reason why they stayed on the team. They were able to establish genuine relationships which many of them are sustained to this day. Coach \#1 stated:

I think that the team succeed in that aspect like at the end of the day, you still have a lot of players hanging out. I see you hanging out with people you've played with before. I have 
friends from 20 years ago, 15 years ago that I still talk to from my team, so whenever I see that at the end of a season, regardless of the results, people want to come back. They were excited about the season because they feel a part of the organization. I think that was very successful because I've been part of losing teams who hated each other at the end of the season. Like they couldn't wait to be done so that they could move on to other teams. And this was different. I felt that at the end of the season, especially our last game. The players were so excited to be a part of it. And a lot of them want to come back to play next year.

RH2: If the team does not have an adequate preseason, it will not be prepared to play as a team, thus it will have difficulty having a successful season.

It is evident, after studying the Andrews University Lady Cardinals, that the team has an issue with time. The season itself is very short considering the amount of time it takes to develop a group of people in light of Tuckman's Group Stages of Development. Most collegiate soccer teams play and practice all year-round. However, The Lady Cardinals meet each other one week before their first game. Coach \#1 stated it as nearly impossible to establish a successful team with that amount of time for preparation. The team is faced with the challenge of not having enough time for growth and development to the point where they are barely reaching their peak performance and the season is over.

Preseason is supposed to aid in not only the physical aspect of team growth but also the relational interpersonal aspect. With that interpersonal development, players will have an established level of trust that will aid them in simply working better together on the field. Unfortunately, this year's preseason attendance was so low that most people did not even classify the preseason as a legit preseason. The phrase, "preseason was nonexistent" appeared in various forms 11 times during the interviews with the whole team. All of the team which includes the 
coaching staff stated that the team did not reach its full potential this year. In fact, 100 percent of the team stated that they needed more development as a team. The preseason for the 2018 soccer season was inadequate and did not aid in successful team building due to the fact that players showed up one week before the first game.

RH3: Players who have positive interactions off the field, play better on the field due to an established level of trust.

The example of player \#11, player \#12, and player \#13 is a prime example of this truth. These three players are very close and from the beginning, they naturally gravitated towards each other. Through observations made, it was clear to me that these players bonded immediately. I notice these players hanging out together outside of soccer even after the season ended. They are always together. While conducting the interviews, these three players were interviewed back to back due to the fact that they were doing homework together at that time.

Consequently, these players had amazing chemistry on the field. I observed them the last game where one of them, player \#12, scored. It was amazing to see how well they passed the ball to each other. One would shout out commands and the other would listen due to that established level of trust. Similar to Messi, Suarez, and Neymar, Barcelona's dangerous trio, these three players (\#11, \#12, and \#13) worked together well because they became best friends.

RQ1: How does the number of match-minutes played affect team members' morale/team spirit?

Players who played the most minutes during the season had boosted morale and team spirit. It came down to experiencing feelings of inclusion in working towards the same goal alongside their teammates. On the other hand, players, such as player \#8, who were constantly on the bench not experiencing the intensity of official matches felt underappreciated by the 
coaching staff. They often questioned whether they should stay on the team and continue going to practices. Player \#8 stated, "Honestly, I never felt motivated to go to practice. [Coach \#3] totally ruined the experience for me by not putting me in to play." Feelings of exclusion associated with the number of minutes played were evident also for player \#16 who only played 21 minutes during the season due to joining the team late. Not only that, but player \#16 shared the confusion during the game because she had not been educated or helped prior to the game. She stated:

One thing that I saw as a new member, I told [one of the coaches] that I had no idea about soccer rules. But [they] didn't tell me the rules. When we went away to play, I was lost when they did the corner kick. I didn't know that I had to go and stand by the post, you know cover the post. When the goalie kicked, we had to be out of the box. I didn't know that. [They] didn't tell me. [They] didn't tell me the basics. I think it's good to communicate and tell the rules to all the new girls who just come late.

In summary, players who played the least felt disconnection to the team because as player \#8 stated, they could not relate.

\section{RQ2: How does external support impact members morale/team spirit?}

External support was reported as one of the greatest factors for the team's success. In fact, players reported that they really valued the outside support especially the support that came from the Men's Cardinals soccer team. Players reported that their encouragement on the sidelines made a big difference as to the amount of effort they would put into the game. They stated how it was so encouraging to see people on the sideline so invested in their game. It made them want to win. One player reported that outside support was one of the main reasons the team won its last game in Ohio. The team had taken another vehicle full of supporters most of which were part of 
the Cardinal men. To take that many people to an away game that was four hours away was very special for the team according to the players. Player \#16 stated, "Outside support was very good for the team. Our supporters were few, but they were shouting like they were a lot of people. I think the supporters contributed big time when we played. The boys especially. I think it's good to take boys and other supporters to the away games."

\section{RQ3: What factors influence the commitment and retention of team members?}

It is interesting to note that "free gear" was not very high on the list of why people stay on the team. The number one reason why players choose to stay on the team is establishing relationships. Again, the team was very close-knit this year. I enjoyed observing them interact with each other. They were all very positive and affirming with each other. Having been on multiple teams myself, and seen different group dynamics even in previous years, I can confirm what all the players stated in their interview concerning the relational aspect of the team. It is true that this year's team was different from years prior. This year's team held a group of women who enjoyed working together and playing together no matter the score and according to coach $\# 1$, the team reached its full potential in the relational, mental side of soccer.

Nevertheless, players reported that ineffective leadership was the number one reason why people leave. Many players shared their experiences with regard to this year's coaching staff. They reported that some coaches were not qualified for the job. However, there were some who the team really valued perhaps more than they will ever know. During the interviews, it was clear to see that the team would have preferred better leadership. In fact, some accredited the other reasons why people would leave, education scheduling conflicts and no outside support, to ineffective leadership. It is evident that communication issues between coaching staff and 
players were present during the season. Organizational issues were also a factor. The team hopes that next year more thought will be taken in the recruitment and selection of coaches.

\section{Recommendations}

\section{Macro Ethnographic Approach}

In regard to having a macro ethnographic approach, or multiple perspectives through various ethnographers, versus me being the sole contributor to this research project, due to the nature of this project, a master's thesis, I chose to complete this study without the aid of other researchers. It would be interesting and perhaps insightful to conduct a similar study through a macro ethnographic approach in order to see how other angles, or perspectives, can provide similar or different results. There is a possibility that a larger number of ethnographers can provide a larger amount of data through more detailed and extensive observations through different point of views.

\section{Effective Organizational Communication}

A significant finding of this study is the role that effective communication plays in any group/team setting. Ineffective communication was shown to be a problem not only between the coaching staff and the players but also amongst the coaching staff itself. The coaching staff is the main guide to the group of players; therefore, it is imperative that there be clear communication amongst the members of the coaching staff in order for there to be clarity in instruction towards the players. Additionally, the findings concluded that ineffective communication stretched further than the team itself. Player \#4 stated, "The Athletic Director would talk to me and I was supposed to talk to [the coach], so I was the contact between them and that happened a lot." Player \#4 is one example of unstructured, unspoken, unestablished communication between the coach and the Athletic Director which should not be occurring unless previously established by 
all parties, the coach, the Athletic Director, and player \#4. Therefore, regarding the structure of the organizational communication, it is clear that it would be beneficial to examine and improve the communication that ranges from coaching staff to the Athletic Director and the Athletic Director to the Office of Student Life.

\section{Mission Statement}

The Andrews University Lady Cardinals soccer team does not currently have a mission statement. This poses a serious problem for the team: lack of purpose. Studies have shown that "developing comprehensive vision and mission statements is seen as critical to the success of organizations in all sectors; [it is] further suggested that organizations with a more comprehensive mission statement do better financially than those with an ambiguous mission or no mission at all" (Brown, Yoshioka, \& Munoz, 2004, p. 29). According to the players, it is evident that the most if not all of the team felt that there was a lack of growth, direction, and communication this season. One recommendation would be to create a mission statement that encompasses these three pillars whilst providing the team with a sense of purpose. For example, Our mission is to be a beacon of love as representatives of Christ through our interactions with others on and off the field as we develop mentally, spiritually, and physically enjoying the sport of soccer.

\section{Male Coach-to-Female Players Relational Dynamics}

One of the reoccurring themes in this study was leadership. According to Fasting and Pfistner (2000), "Male coaches are more often characterized by a 'masculine' style of interaction, and there is a feeling of not having been taken seriously by male coaches. Players seemed to have been more satisfied with female than male coaches, because of their female style of communication" (p. 91). Participants in the study also expressed similar sentiments. 


\section{Title IX}

During the season, one of the things that was very clear was the inequality between the men's team and the women's team. Many players also noticed this and decided to share their thoughts during the interviews. Their experiences are as follows:

Player \#8:

I think we don't have a lot of support like I see Andrews put on their Instagram they were promoting for like the boys' soccer game, but I never saw anything for the girls' soccer games. And uh it seems like we're kind of given like the leftovers of what they can give us... for traveling... for things like that. Which honestly, it's appreciated because I mean we did have good experiences with the food and things like that, but they get like so much stuff and like it's not even about the stuff... it's just like give it to everyone or don't give it to anyone because then the girls will just feel like, "Why are they more important than us?"

\section{Player \#4:}

Also, this is what really pisses me off. There was so much inequality between the boys' team and the girls' team this year. Like I know last year they really made a point of like saying, "Oh we're going to switch the days we get the fields." That barely happened this year, it only happened towards the end of the season, but at the beginning, we were on the crappiest field. It wasn't even mowed. We didn't have anything. We were out there in like potholes. And the guys would watch us and be like, "Oh I feel bad for them." They would say things like that, but nobody would do anything. We weren't given warm-up shirts, the guys were. And every time I would ask the girls like, "Guys can we do something about this? It can't just be me complaining, we have to say something about this." This is gender inequality, and it starts small, but it is also at a greater scale, and for a university that praises 
itself for being the most diverse in America this is a big issue. And they need to address this issue. Like sure we didn't win a game last year. Sure, sure, but that doesn't give us a reason to be mistreated or disrespected. This year we won two games, so like if that's the reason you didn't take us seriously, you need to take us more seriously. Also, I made a big fuss about this at the beginning of the year and people thought I was a little crazy, but the uniforms didn't fit, they only had smalls. They didn't have mediums, they didn't have larges. Literally whoever order the socks got so many smalls, that we had a whole bunch of smalls, and some girls didn't even get any socks because they were like, "I'm a medium, I'm not a small." There was no asking of what sizes we needed. It was just the assumption that since we're girls, we're smalls. Completely crazy right? I know it's fine like usually we get changed on the field, but girls didn't like that this year. We were very uncomfortable to do that. So, we actually all wore our jerseys on the field, and if we had to change, we would run to the bathroom. So, I think that's okay though, you should have the ability to not have to do that. So, I don't know if we could have a system where we can have a locker room. There's just so much discrepancy that happens and like you have to do it for all. At least [our coach last year] tried to get us warm-ups, and even though it was like the intramural's shirts like he tried. I think he realized it. And he was very strict about getting us that good field on the days we were supposed to get it, but also, why is it the guys get it Monday, Wednesday, Fridays, and the girls only get it on Tuesdays and Thursdays? Why doesn't it rotate every year, so that every girl gets a chance to have 3 days to have that field? Like why are we on the bad field 3 days a week? What makes them better than us? From my understanding, we might have even had a better season this year. So, I don't understand. So that should be fixed. Women's rights! That was my biggest issue. When we were taking 
the pictures, they only had smalls, and I was like I don't mind taking a picture in this, but I'm not going to play a sports game in this like my shorts are going up, my shirt's going up, I feel super uncomfortable. And it's not just me like I'll deal with it or whatever. But these girls like no girl should feel uncomfortable wearing the clothes that the school gave them just because they don't have her size. We're not asking for anything crazy, we're just asking for a medium and a large. It ain't rocket science.

\section{Player \#15:}

The attitude of the people in leadership positions, not just the coach, needs to change because I understand we're not the greatest team, but at the same time, just because we're girls doesn't mean that we can't play soccer. We can keep up with the guys easily. Like we're given so many fewer games than they have. Like there are no team workouts or a wholistic schedule. All we get is like 2 hours on the field which may or may not be worth your time. Tryouts would help because then you can figure out who is right for the team. Like we don't have the resources. They don't give a crap about the girls' teams. I mean if the team's not good yeah you don't want to dump a whole bunch of money on them, but at the same time, you can't deprive them of money. Like they don't even have the equipment and like as far as I know, they don't even have captain armbands. That's like a basic for any team. Like Literally they're like 5 dollars and we don't have them. I didn't even know we had a ladder until this season. We didn't even have it until the middle of the season like I think the guys had it. I don't know.. we have balls that aren't even round anymore. They're ovals; ladders that are breaking all over the place, and the mannequins are broken. Our nets are crap on the practice field. They're bent. There're holes in everything. Yeah, the guys are definitely given priority. We need more money, more resources. 


\section{Player \#5:}

You can definitely tell that the school puts more effort into the guy's teams. The soccer team used to be good. Like they were good before I got here. They were really good. Also, just simply like promoting the team as well. When I had just gotten here, nobody knew about soccer. I'd be like, "Oh I'm going to soccer," and they'd be like, "What are you talking about? Like there's a team?" and I'd be like, "Yeah.” And I'd try to get some people to join. So just like putting ourselves out there. Like soccer wasn't out there... like basketball if anything else. I don't know if you have AUSA on Instagram, but they posted the schedule on Instagram and I'm like dang what about soccer? That's just interesting. Soccer is so underappreciated in a sense especially women's soccer.

The team would appreciate further study regarding Title IX and the team. According to Jackson (2014), "Title IX of the Education Amendments Act of 1972 is a federal law that states: 'No person in the United States shall, on the basis of sex, be excluded from participation in, be denied the benefits of, or be subjected to discrimination under any education program or activity receiving Federal financial assistance." As someone who has witnessed and experienced gender discrimination, it would be a great topic for further study and discussion.

In conclusion, I enjoyed conducting ethnographic research on the Andrews University Lady Cardinals soccer team for the 2018 season. It is evident that in a sport's team, success is not only a result of a group of people forming together. Success comes with a variety of different factors. Some of the main elements I found that affect the success of teams are communication, time, resources, support, genuine friendships, and most importantly leadership. Hopefully, in taking these under consideration, coaches and players can increase the chances of having successful seasons to come. 


\section{References}

Brown, W., Yoshioka, C. F., \& Munoz, P. (2004). Organizational Mission as a Core Dimension in Employee Retention. Journal of Park \& Recreation Administration, 22(2), 28-43.

Bubpa, N., \& Nuntaboot, K. (2017). Understanding Life Scenarios of Older People in Society of a Northern Thai Community: Ethnography Research. Suranaree Journal of Science \& Technology, 24(3), 367-378.

Conflict. (n.d.). Retrieved March 15, 2019, from https://www.merriamwebster.com/dictionary/conflict

Damo, A. S. (2014). Training soccer players in Brazil. Soccer \& Society, 15(1), 93-107.

Das, A. (2019, March 08). U.S. Women's Soccer Team Sues U.S. Soccer for Gender Discrimination.

Ebert, B., Miskowiak, K., Kloster, M., Johansen, J., Eckholm, C., Wærner, T., ... Bruun, L. M. (2017). An ethnographic study of the effects of cognitive symptoms in patients with major depressive disorder: the IMPACT study. BMC Psychiatry, 17, 1-13.

Fasting, K., \& Pfister, G. (2000). Female and male coaches in the eyes of female elite soccer players. European Physical Education Review, 6(1), 91.

Hautmann, T. (2016, February 09). Power of Three: The best attacking trios of all time.

Ishii, K. (2010). Conflict Management in Online Relationships. CyberPsychology, Behavior \& Social Networking, 13(4), 365-370

Jackson. (2014, January 27). Title IX Frequently Asked Questions.

Moreira Praça, G., Manuel Clemente, F., de Andrade, A. P., Perez Morales, J. C., \& Juan Greco, P. (2017). Network Analysis in Small-Sided and Conditioned Soccer Games: The Influence of Additional Players and Playing Position. Kinesiology, 49(2), 185-193. 
Neville, J. (2019). Dressed to play: An analysis of gender relations in college women's ultimate Frisbee. International Review for the Sociology of Sport, 54(1), 38-62.

Newins, A. R., Bernstein, E., Peterson, R., Waldron, J. C., \& White, S. W. (2018). Title IX Mandated Reporting: The Views of University Employees and Students. Behavioral Sciences (2076-328X), 8(11), 106.

Okamura, J. Y. (2009). Ethnographic Research Methods. Nepalese Journal of Qualitative Research Methods, 3, 28-37.

Posada, S. (2017). Group dynamics for teams: fifth edition. Educational Psychology in Practice, 33(1), 106.

Ross, T. F. (2015, April 09). What Gender Inequality Looks Like in Collegiate Sports.

Scherrer, J. L., Olcoń, K., Butterfield, A. K., \& Kebede, W. (2016). Bringing experiential educational groups to the United States: an analysis of group development in an international travel and study program. Social Work Education, 35(6), 693-705.

Van Doesum, N. J., Van Prooijen, J., Verburgh, L., \& Van Lange, P. M. (2016). Social Hostility in Soccer and Beyond. Plos ONE, 11(4), 1-13.

Van Swol, L. M., \& A., A. (2019). Language and Group Processes: An Integrative, Interdisciplinary Review. Small Group Research, 50(1), 3-38. 
Appendices

Appendix A

Recruitment Flyer for the 2018 Andrews University Soccer Team

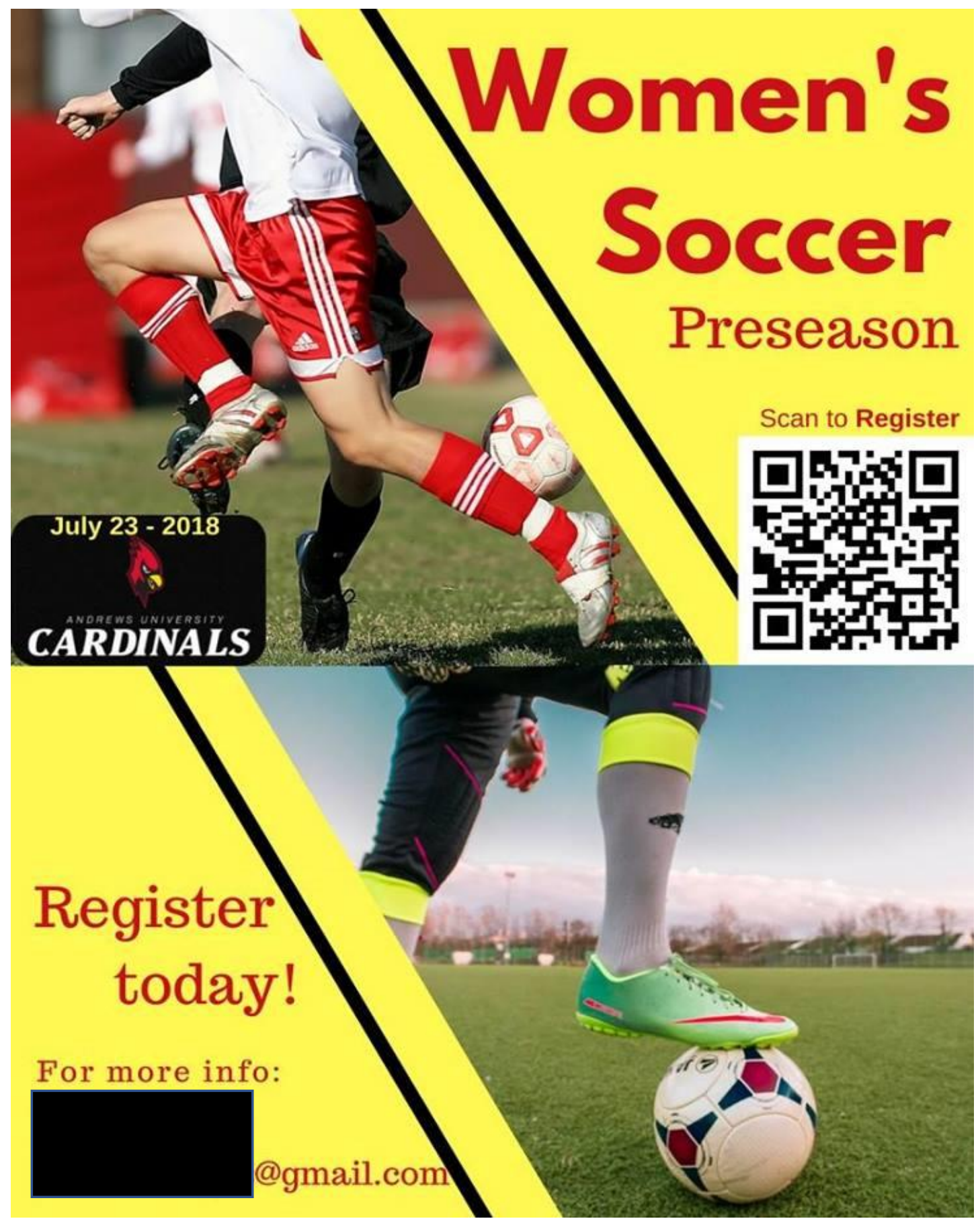




\section{Appendix B}

\section{Soccer Season Head Coach Ethnography Endorsement Letter}

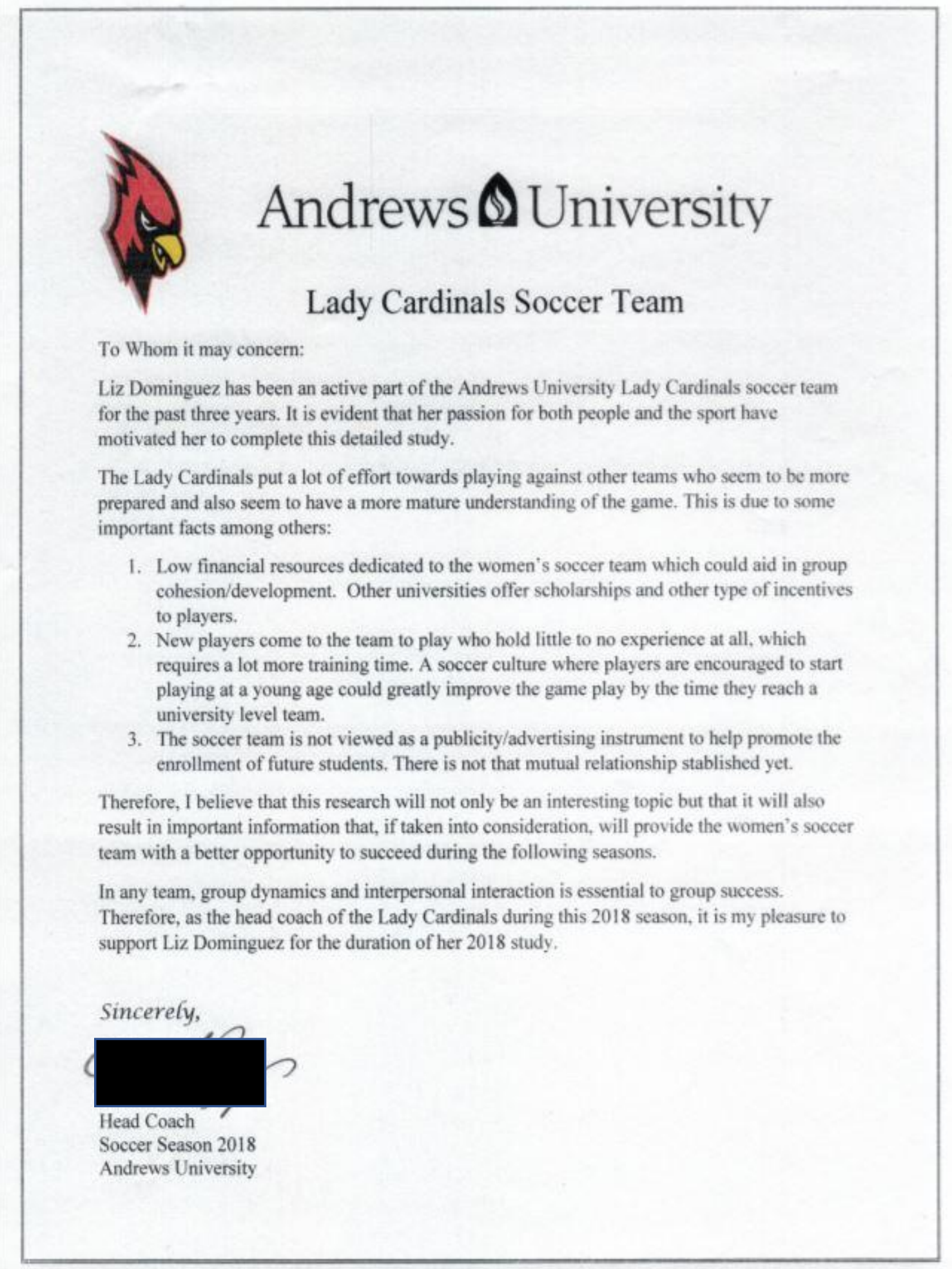


Appendix C

Ethnographic Study Participant Informed Consent

Andrews University

\section{INFORMED CONSENT FORM}

I, Liz Dominguez, am conducting a research study in partial fulfillment for my Master's of Communication degree at Andrews University, Berrien Springs, Michigan. Your participation in this study is greatly a appreciated.

\section{Research Title:}

AN ETHNOGRAPHIC STUDY: ANDREWS UNIVERSITY LADY CARDINALS SOCCER TEAM AND GROUP DYNAMICS

\section{Purpose of Study:}

The purpose of this study is to understand the different factors that play into how a team works and where the Andrews University Lady Cardinals soccer team falls short. It is my intent to understand the various group dynamics that take place in a team setting and the value that each stage of a group coming together holds.

\section{Duration of participation in study:}

I, , understand that I will be observed as an individual who holds an active role within the soccer team. As a participant in the 2018 soccer season, I understand that being an active player on the team will require me to take time out of my day to come to practices and games. This will take approximately 15 to 20 hours of my time weekly.

\section{Benefits:}

Subjects are allowed 10 co-curricular credits for being an active member of the soccer team. Subjects are also allowed one credit hour as an alternative to a physical activity course at Andrews University if they have not already completed the one-credit course through previous years in the soccer team. Besides these, there are obvious health benefits that come with playing soccer such as an increase in cardiovascular endurance and the release of endorphins which cause the subjects to feel happier after a session of soccer training. At the end of this study, the goal would be to understand what can be improved for next year's Lady Cardinals Soccer team so that the team can be more successful and connected overall and that each player can honestly say that they have improved in at least one aspect of soccer whether it be pertaining to skills, relationships, or physical, mental or emotional health.

\section{Risks:}

Soccer is a contact sport which means that soccer players are encouraged to play using their physical strength. In any contact sport, there is always the risk of injury. Subjects of this research will be developing their soccer skills and soccer IQ (the knowledge of the game to make plays and such). Not only that, but participants will be playing in tough competitive games against other schools. Therefore, there is no promise that subjects will not obtain an injury either in practice or in official matches as is the case in any sport. 


\section{Voluntary Participation:}

I have been informed that my participation in this study is completely voluntary. I am aware that there will be no penalty if I decide to cancel my participation in this study, and that there will be no cost to me for participating in this study.

Confidentiality: I understand that my identity in this study will not be disclosed in any published document and that any observations made will not be so descriptive to the point where people are informed enough to know my identity. I am aware that the researcher will keep the records for at least 5 years.

Contact: I am aware that I can contact the researcher's advisor Desrene Vernon-Brebnor at desrene@andrews.edu or the researcher herself at lizd@andrews.edu answers to questions related to this study.

I have read the contents of this Consent and received verbal explanations to questions I had. My questions concerning this study have been answered satisfactorily. I hereby give my voluntary consent to participate in this study. I am fully aware that if I have any additional questions I can contact Liz Dominguez or Desrene Vernon-Brebnor.

Signature

(Subject)

Date

Researcher Signature

Phone

Date 


\section{Appendix D}

Andrews University Lady Cardinals Soccer Team Observation Chart for the 2018 Soccer Season

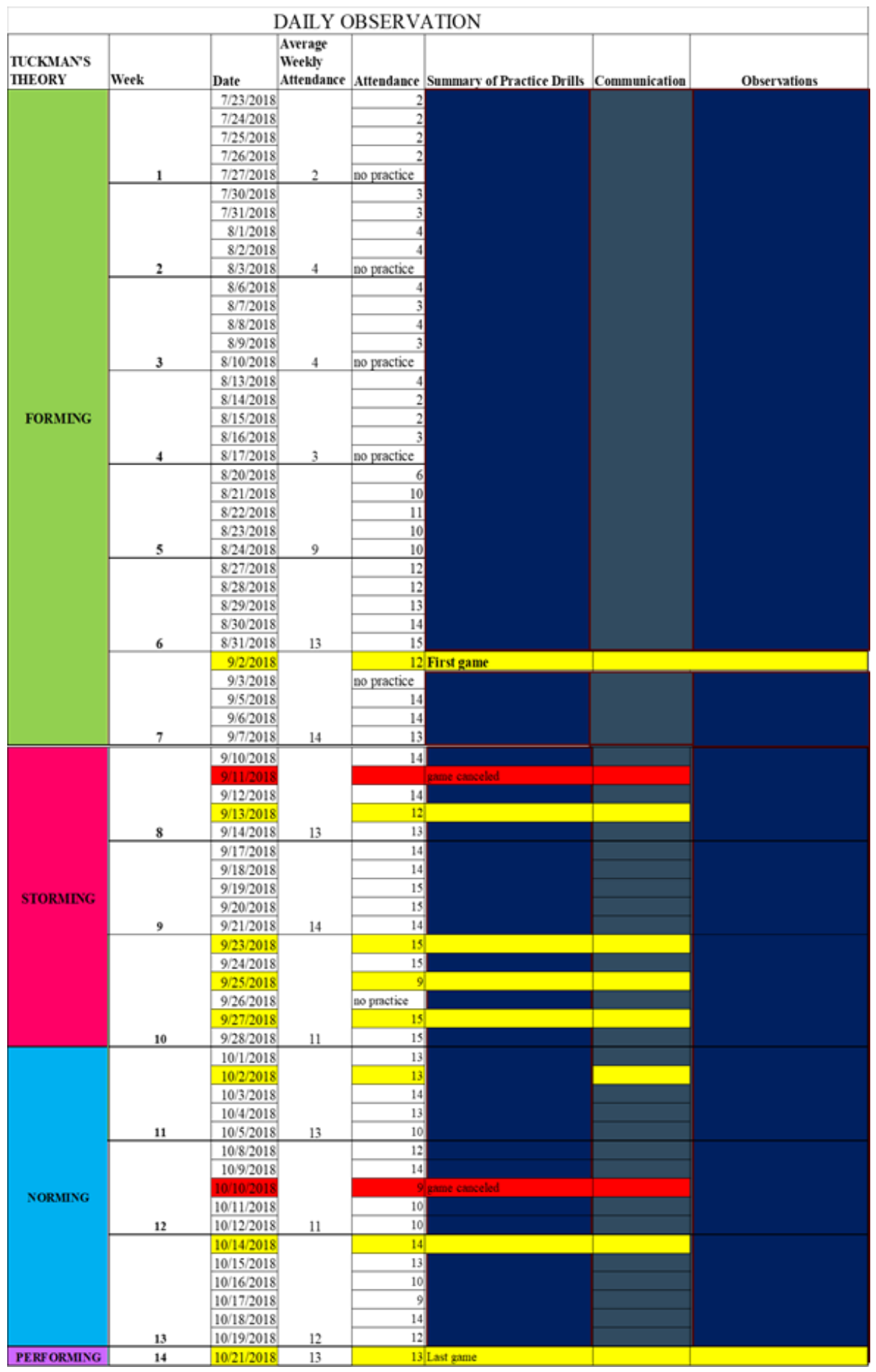


Appendix E

Interview Questions

1. What would you say is your soccer experience prior to this season?

2. Have you enjoyed your time with this team?

3. In your opinion, who is the most knowledgeable?

4. Who participates when decisions are made and whose opinion is sought? Who do you go to for help?

5. What topics are openly discussed versus what topics are clearly off-limits or avoided both between you and your coach, and you and your teammates?

6. What are some things that you would hear during the season that were positive and negative? (inclusive communication vs. Exclusive communication)

7. How are disagreements handled?

8. Which team members support each other? (including your teammates) Who are your besties on the team? What other "groups" can you see present on the team?

9. Who talks the most versus who listens the most (in general)?

10. How does the leader facilitate the group (can you tell me about his communication style)?

11. What are your thoughts on the team's preseason?

12. What factors helped the team succeed in your opinion?

13. Are there certain players that you believe were more valued by the team/coach in comparison to others?

14. What factors influence the commitment and retention of team members?

15. Do you think the team reached its full potential? Why or why not?

16. What can be done to improve the team?

17. Any last comments/ Describe the season in 1 Word. 